\title{
What drives corporate default risk premia? Evidence from the CDS market
}

\author{
A. Díaz, J. Groba and P. Serrano*
}

April 10, 2011

\begin{abstract}
This paper studies the evolution of the default risk premia for European firms during the years surrounding the recent credit crisis. We employ the information embedded in Credit Default Swaps (CDS) and Moody's KMV EDF default probabilities to analyze the common factors driving this risk premia. The risk premium is characterized in several directions: Firstly, we perform a panel data analysis to capture the relationship between CDS spreads and actual default probabilities. Secondly, we employ the intensity framework of Jarrow et al. (2005) in order to measure the theoretical effect of risk premium on expected bond returns. Thirdly, we carry out a dynamic panel data to identify the macroeconomic sources of risk premium. Finally, a vector autoregressive model analyzes which proportion of the co-movement is attributable to financial or macro variables. Our estimations report coefficients for risk premium substantially higher than previously referred for US firms and a time varying behavior. A dominant factor explains around $60 \%$ of the common movements in risk premia. Additionally, empirical evidence suggests a public-to-private risk transfer between the sovereign CDS spreads and corporate risk premia.
\end{abstract}

JEL classification: $G 12, G 13, G 32$

KEYWORDS: Default risk premium, CDS, EDF, risk neutral default probability, actual default probability

\footnotetext{
${ }^{*}$ Correspondent author. A. Díaz acknowledges the financial support from the grant JCCM PCI08-0089-0766. P. Serrano acknowledges the financial support from the grants P08-SEJ-03917 and MEC ECO2008-03058. J. Groba and P. Serrano are from Department of Business Administration, University Carlos III, 28903 Getafe (Madrid), Spain. E-mail: jonatan.groba@uc3m.es (J. Groba) and pedrojose.serrano@uc3m.es (P. Serrano). A. Díaz is from Department of Economic Analysis and Finance, University of Castilla La-Mancha, 02071 Albacete, Spain. E-mail: antonio.diaz@uclm.es. The usual caveat applies.
} 


\section{Introduction}

This paper mainly addresses the evolution of the corporate default risk premia (RP, hereafter) for a sample of single-name European credit default swaps (CDS) during years 2006-2010, a period which allows analyzing the dramatic changes that risk premia behavior shows during the financial crisis. We proxy the risk premia by the ratio of estimated risk-neutral to actual probability of default. We employ the information embedded in CDS prices and Moody's KMV expected default frequency (EDF) to learn about how investors are assessing the risk of changes in bond prices under widespread default circumstances. In this way, we explore the presence of common factors across firms that might affect those default premia and which portion of this co-movement is attributable to financial or macro variables. Additionally, we also stress the link between corporate and sovereign default risk, quantifying the impact of shocks in sovereign risk on corporate risk premiums.

The credit derivative market has grown much faster than other derivative markets, and the size of the credit derivatives market has increased from US\$900 billion in June 2000 to US\$30 trillion in December 2009 although it reached US\$62 trillion in December 2008. ${ }^{1}$ The size of the CDS market shrank significantly since the second half of 2008. The failure of Lehman Brothers forces a declining in number of participants. Additionally, banks participate in "termination cycles", leading to the compression of redundant positions through multilateral terminations. In this context, Europe accounts for a significant share of the global CDS market in terms of geographical focus of products -around 40\% of CDS index products are based on European entities-, market share of dealers $-66 \%$ and $50 \%$ of the dealers contributing to calculation of the iTraxx Europe indices and the CDX indices are domiciled in Europe, respectively-, and currency denomination around $39 \%$ of CDS are denominated in Euros. ${ }^{2}$ Besides major concerns about transparency and counterparty risk from credit crisis, these instruments have increased popularity and liquidity during this decade. Credit derivatives in general, and CDS in particular, have become the market standard for assessing the creditworthiness of a large number of corporates. In addition, credit derivatives have made credit risk trading swift and easily accessible.

The empirical literature on the determinants of CDS returns or CDS spreads is still limited although

\footnotetext{
${ }^{1}$ Notional amounts outstanding in all surveyed contracts according to ISDA Market Survey 2010.

${ }^{2}$ ECB (2009)
} 
a number of recent papers address this topic ${ }^{3}$. Also, CDS written on European government debt or on European firms are receiving an increasing attention by academics, see Dieckmann and Plank (2010) and Berndt and Obreja (2010) respectively. In this context, the literature about default premium is even more scarce. We analyze the degree of variation over time in the price for bearing risk in European firms and their determinants in conditions of deep financial and economic crisis. We adapt the main idea underlying in Jarrow et al. (2005), Driessen (2005) and Berndt et al. (2005) in order to obtain a risk premium from the ratio of the risk-neutral to the actual probability of default. Driessen (2005) estimates the relationship between actual and risk-neutral default probabilities, using U.S. corporate bond price data, and assuming that conditional default probabilities are equal to average historical default frequencies by credit rating. Berndt et al. (2005) follow a two-step procedure, first estimating the actual default intensity model parameters with monthly Moody's KMV EDF measures of default probability, and then estimating the risk neutral intensity model parameters with weekly U.S. CDS rates and EDFs. Our approach is consistent with the theoretical framework in Jarrow et al. (2005) that assumes a CIR model. Thus, it avoids the possibility of negative intensities and allows to obtain closed-form expressions of default probabilities. We minimize the squared distance between the empirical and theoretical values to estimate the CIR parameters. One advantage of our estimation of the risk neutral and real intensities is that we estimate both intensities simultaneously with daily 1-, 3- and 5-year CDS spreads and 1-, 3- and 5-year EDF. Additional references on reduced-form pricing models for bonds and CDS are Duffie and Singleton (1999), Duffee (1999), Longstaff et al. (2005) and Pan and Singleton (2008), among others.

Our data is composed by daily spreads of the most liquid 1-, 3- and 5-year CDS contracts for senior unsecured debt of European investment-grade firms. ${ }^{4}$ Literature traditionally assumes that CDS rates represent somewhat fresher price information than do bond yield spreads. These instruments are less likely to be affected by market illiquidity than are bond yield spreads. This fact has induced researchers and practitioners to use CDS spreads as pure measures of default risk (for example; Blanco et al., 2005; Longstaff et al., 2005).

However, recent papers (e.g., see Tang and Yan, 2007; Das and Hanouna, 2009; Bongaerts et al., 2010) find that part of the CDS spread reflects liquidity effects. Bedendo et al. (2009) observes deviations of the

\footnotetext{
${ }^{3}$ For instance, Chen et al. (2005), Tang and Yan (2007), Cremers et al. (2008), Das and Hanouna (2009), Ericsson et al. (2009), Zhang et al. (2009) and Bongaerts et al. (2010).

${ }^{4}$ In the market, $91 \%$ of single-name CDS contracts refer to non-sovereigns in terms of amount outstanding and the $67 \%$ of these single-name CDS contracts are investment grade.
} 
CDS market spreads from the theoretical fair values obtained from a structural model. The gap between the two is time varying and widens substantially in times of financial turbulence. Proxies of equity volatility, implied volatility skew and CDS liquidity show a significant impact on the gap. Even the ECB (2009) scruples the CDS price information reliability for pricing purposes in times of distress. They comment the low levels of liquidity resulting from the crisis and adduce possible over-concentration in the sense of a scarcity of sellers. A reduced number of counterparties results in increased concentration risk and, consequently, greater systemic risk. ${ }^{5}$ Considering this information, we assume that the theoretical default risk premium obtained from the model is a biased measure in times of financial turmoil. We interpret the ratio of estimated risk-neutral to the actual probability of default as a risk premium proxy which incorporates an illiquidity compensation on top of the compensation for default event risk. In this way, our approach is close to Longstaff (2011) where liquidity premium is embedded on default intensity. As robustness, we introduce a liquidity proxy to check if it is affecting our estimations of RP.

The European case provides a privileged observer position for several reasons. The recent financial crisis is the first challenge to the European Union (EU) since its foundation in 1992. Although the monetary union exists from 2001, the impact of the crisis in the EU members has been heterogeneous, as shown by the public debt crisis on Greece, Ireland, Italy, Portugal and Spain since early 2010. How firms' debt has been affected by the behavior of local economic policies is a matter of interest. This question is attainable by direct comparison of equally-rated EU firms, where companies on different state members could help us to disentangle the corporate default risk from that inherent to its own country. In this way, addressing the constituents behind the risk premium is important in order to implement policy measures oriented to a stability framework.

With regard to investors, an analysis of risk premium could provide additional answers to whether or not default event risk is diversifiable, which may have implications for bond pricing, risk management and portfolio allocation strategies. Credit event risk is purely idiosyncratic when investors are risk-neutral and the expected return of a risky bond equals the expected return on a default free bond plus a function of the risk-neutral mean-loss rate. In this way, actual and risk-neutral probabilities are equal and no premium due to changes in bond prices under default circumstances appears, as pointed out by Jarrow et al. (2005). The

\footnotetext{
${ }^{5}$ ECB (2009) comments: "In the period of financial market stress, as well as a higher liquidity risk premium and falling recovery rates, CDS spreads may also have been affected by other risk premia, such as for jump-to-default risk and systemic risk, which in normal times have a negligible impact on the level of CDS spreads."
} 
work of Driessen (2005) provides the first empirical evidence that default event risk premium helps to explain the expected corporate bond returns, but this work is not successful in obtaining an accurate measure of its size nor its time series behavior. Our results seem to confirm the existence of, at least, four different common factors which drive the $80 \%$ movement of the risk premium in the sample under study. This fact could be interpreted as an important fraction of systematic risk is being priced in the market via default event premium.

Finally, from an academic point of view, the analysis of risk premium using credit derivative products is quite recent, and it has been mainly focused on U.S. firms and pre- crisis periods (Berndt et al., 2005). However, its extension to European firms or longer time spans is nonexistent. Unlike to previous articles, our sample comprises CDS data for almost one hundred European firms in a broad period from 2006 to 2010, covering the recent subprime crisis. Our portfolio is composed by a well-diversified set of investment grade firms across ten sectors and different countries. Additionally, we have at our disposal valuable information on real probabilities of default as those provided by Moody's. To our knowledge, this is the first article that analyzes the RP in European firms and searches the main drivers of this RP.

This article contributes to the existing literature in several ways. Firstly, we analyze the risk premium of European firms in line with Driessen (2005) and Berndt et al. (2005) for US firms, covering a period which comprises the recent financial crisis 2006-2010. Secondly, this work is pioneer in studying the relationship between risk premium and macro- and financial variables, quantifying how financial shocks affect the risk premium. There seems to be a public-to-private risk transfer not documented before, since shocks in the sovereign CDS market lead to shocks in the risk premium demanded by corporate investors.

Summarizing, this article studies the risk premium embedded in European CDS, analyzing its relationship with financial variables and emphasizing the sovereign ones. The remainder of this article is organized as follows. Section 2 shows the main features of European CDS data. Section 3 focuses on the EDFs and explores its relationship with CDS spreads. Section 4 provides the theoretical framework of risk premia. Section 5 presents the econometric framework, and Section 6 analyzes the economic variables involved in the risk premium. Finally, Section 7 draws some conclusions. 


\section{The characteristics of European CDS data}

This section defines the Credit Default Swap contract and the structure of the European market. We also outline some stylized facts of European single-name CDS.

\subsection{Definition of CDS}

A Credit Default Swap (CDS) is a contract between two parties to receive insurance against the default of a certain bond (reference entity). Within a CDS, the insured (protection buyer) is willing to pay a certain percentage (spread) over the total amount of the bond (notional) to the insurer (protection seller). This annual spread is usually paid quarterly up to the maturity of the contract, if there is no default. Otherwise, the protection seller perceives the defaulted bond, restoring its amount to the protection buyer.

Longstaff et al. (2005) or Pan and Singleton (2008), among others, provide formulas for the price of a CDS contract $\left(C D S_{t}(M)\right)$ with maturity $M$ in an intensity based setting,

$$
\frac{1}{4} \operatorname{CDS}_{t}(M) \sum_{i=1}^{4 M} E_{t}^{\mathbb{Q}}\left[e^{-\int_{t}^{t+.25 i}\left(r_{s}+\lambda_{s}^{\mathbb{Q}}\right) d s}\right]=L^{\mathbb{Q}} \int_{t}^{t+M} E_{t}^{\mathbb{Q}}\left[\lambda_{u}^{\mathbb{Q}} e^{-\int_{t}^{u}\left(r_{s}+\lambda_{s}^{\mathbb{Q}}\right) d s}\right] d u
$$

where $r_{t}, \lambda_{t}^{\mathbb{Q}}$ and $L_{t}^{\mathbb{Q}}$ refer to the risk-free interest rate, default intensity and Loss Given Default (under the recovery of face value assumption) of the referenced bond under the $\mathbb{Q}$ measure at $t$. A deeper discussion of the intensity process is provided in Section 4. The left-hand side of (1) indicates the (quarterly) premium on the sum of expected discounted cash-flows received by the protection seller. The right-hand side is the expected discounted payoff received by the protection buyer if the bond defaults. Single-name CDS contracts are written without upfront payments, which equals both sides of (1). Chen et al. (2005) also models CDS contracts that incorporate a liquidity premium spread, in agreement with recent evidence that CDS spreads might also incorporate a liquidity component.

\subsection{Descriptive Statistics}

Our data is taken from Markit Group Ltd., a comprehensive database which is becoming extensively employed in academic articles because its high quality standards to create a composite CDS spread save from staleness. Our sample is composed by daily spread quotes of 1-, 3- and 5-year CDS contracts for 95 European 
firms with available EDF measures, from 01/Jun/2006 to 31/Mar/2010. We have taken the CDS belonging to Senior Unsecured Debt, denominated in euros and with modified-modified (MM) restructuring clause ${ }^{6}$, usual in European contracts (see Berndt and Obreja, 2010). The structure of European CDS market is analyzed in ECB (2009) and Berndt and Obreja (2010).

As shown in Table 1, our sample is composed by high quality firms distributed along ten different sectors -Basic Materials, Consumer Goods, Consumer Services, Financial, Health Care, Industrials, Oil \& Gas, Technological, Telecommunications and Utilities- and fourteen different countries -mainly from Germany, France and UK. We fix high quality requirements to our sample period: the percentage of missing observations must not exceed the $15 \%$ and the longest series of consecutive missing spreads must be 10 days or less, following the criteria of Schneider et al. (2009). Our sample mainly comes from Financial and Consumer Services, which represent around the $34 \%$ over the total number of firms. Regarding their credit quality, all the companies are investment-grade. Half of the sample (45 firms) comes from firms with ratings from AA to A, and the other half (50 firms) comes from BBB-rated firms. This means that even though we have a large sample period that covers a wide number of firms across different sectors and countries, our conclusions mainly concern to investment grade firms.

\section{[INSERT TABLE 1 ABOUT HERE]}

Table 2 includes a summary of the main statistics for the 5-year CDS spreads. The last three columns represent the longest series of consecutive missing spreads, percentage of missing values, and percentage of days with zero increment over the previous day, respectively. We highlight that an average firm in the sample has a median spread of 71 bps. The market perceives utility firms as firms with better credit quality than financial firms, even though these last have better rating in general. By contrast, an average firm from the Basic Materials sector has the highest mean and volatility in CDS spreads. Regarding the time series behavior of spreads, autocorrelation coefficients for the spread changes are higher than 0.20 , which reveals a strong serial persistence in data and means that past changes in spreads are an important source of information when determining the current spreads.

\footnotetext{
${ }^{6}$ Mainly, there are three credit events: bankruptcy, failure to pay and restructuring. Since restructuring can happen in several ways, the restructuring clause standardizes what is qualified as credit event and its settlement conditions. Under MM clause, the restructuring agreements are considered credit events, and deliverable bonds must have a maturity lower than 60 months for restructured obligations and 30 months for other obligations.
} 


\section{[INSERT TABLE 2 ABOUT HERE]}

At last, because in good quality firms is difficult to be precise in estimating their recovery rate (percentage of par value recovered by the bond owner in the event of default) and its time variation, Markit tends to assume a $40 \%$ recovery rate, as the summary table shows. This is a general assumption that will be recurrently used in this paper, whose consequences will be discussed later on.

\subsection{Two-sample Tests}

We have already suggested the importance of sectors when it comes to compare the level and behavior of CDS premia. One question that may arise us is whether there are other characteristics or events that might affect to the joint level of the CDS spreads in terms of higher medians or standard deviations. These differences could arise because of its membership to a certain groups or classes such as ratings or regions, among others.

To analyze the former question, we group the data in four data categories (average rating, regions, sectors and time), performing some non-parametric tests to look for differences in variances (scale) and medians (location) between groups. Table 3 shows the outputs for the Ansari-Bradley (AB) test of equal variances and the Wilcoxon-Mann-Witney test (WMW) of equal medians ${ }^{7}$.

\section{[INSERT TABLE 3 ABOUT HERE]}

Concerning to rating and time categories the $\mathrm{AB}$ test tells us that, as expected, lower rating firms and/or those dates after BNP Paribas froze three investment funds in 09/Aug/2007 have more volatile spreads and spread increments. However, no conclusion on the median of these two groups can be drawn, since the WMW test requires equal variances in both groups, which has been previously rejected.

Regarding sector and region grouping, results are quite contradictory. For example, firms from PIGS countries (Portugal, Ireland ${ }^{8}$, Greece and Spain) have a more stable credit market (less volatile spreads). Commodity firms had higher volatility than others, and Financials had lower volatility than other sectors. But perhaps the consequences from BNP Paribas' freezing and other events during the financial crisis made Financials to have higher volatility of spread changes. It is important to point out that these conclusions

\footnotetext{
${ }^{7}$ Parametric tests have not been performed since normality is strongly rejected in all of the groups. We also perform a Kolmogorov-Smirnov (KS) test that rejects in all cases the hypothesis that both groups have the same distributions. Results are available upon request.

${ }^{8}$ Notice that there is not any representative firm from Ireland in our CDS sample.
} 
could be intended since our sample is biased towards good quality firms. For instance, the fact that the PIGS countries where more stable in terms of volatility may only imply that the few firms (8.42\%) in our sample are good quality firms that did not suffer the consequences of the financial crisis as perceived by credit investors.

\section{A first approach to the problem}

Economically, the risk premium of CDS measures the premium that investors are willing to pay to be hedged against the event of default. Thus, we are interested in how the actual probabilities of default are translated to CDS spreads. A first approach to the problem consists on analyzing the relationship between CDS spreads and actual default probabilities. This section presents some foundations of the EDFs and examines its relationship with CDS spreads by means of some panel regressions.

\subsection{Expected Default Frequencies (EDF)}

\subsubsection{The Merton (1974) model}

Literature usually employs the Expected Default Frequencies (EDF) of Moody's KMV as a proxy for actual default probabilities. Its accuracy for predicting default has been previously analyzed in the industry and academia by Crosbie and Bohn (2003), Kealhofer (2003), Dwyer and Qu (2007), Korablev and Dwyer (2007) or Bharath and Shumway (2008), among others.

In general, the EDFs have higher predictive power than ratings because ratings are measures of default risk independent of the business cycle, but EDFs depend on stock prices and are time-variant. To show its high performance, Kealhofer (2003) shows that EDFs correctly identify $72 \%$ of defaults and credit ratings only $61 \%$. Bharath and Shumway (2008) concludes that $65 \%$ defaulting firms had probabilities in the higher decile during the quarter they default and hazard models that include Merton's default probabilities have better out-of-sample performance. Korablev and Dwyer (2007) validates the EDF's default predictive power by computing the accuracy ratios, and tries to validate the level of EDF measures comparing the predicted default rates with the realized default rates through a simulation exercise. Additionally, EDFs usage for determining the default premium has been also referred in Berndt et al. (2005) for US corporate CDS spreads, in Vassalou and Xing (2004) for stock prices or Pan and Singleton (2006) for Japanese banks' CDS spreads. 
The EDF measurement is based on the Merton (1974) model. Merton's model assumes that the firm's assets follow a Geometric Brownian Motion (GBM)

$$
d V_{t}=\mu_{V} V_{t} d t+\sigma_{V} V_{t} d W
$$

where $V_{t}$ represents the value of the firm at time $t, \mu_{\mathrm{v}}$ is the firm's assets growth rate and $\sigma_{V}$ the volatility of the firm's value. Merton (1974) considers that firm's stockholders purchase an European call option with strike price equals to the debt value, and it can be proved that the default probability over the next $T$ periods stands for

$$
p\left(V_{T}<F\right)=N\left(-\frac{\ln \left(V_{T} / F\right)+\left(\mu_{V}-\frac{1}{2} \sigma_{V}^{2}\right) T}{\sigma_{V} \sqrt{T}}\right)=N(-D D)
$$

with $F$ the face value of the debt and $T$ the maturity of the debt. Whenever the value of the firm falls below the value of the debt, stockholders cannot pay back the debt, and bondholders receive the value of the firm.

Expression (3) is the basis for the Moody's KMV estimates of EDF (expected default frequency). DD stands for the distance to default measure; it serves as rank of default likelihood, and the normal distribution maps the DD into default probabilities. The problem is that the estimations of default probabilities with the Normal distribution do not match the historical default rates. This problem has been documented in Vassalou and Xing (2004), where they talk about Default Likelihood Indicator (DLI) and not real default probabilities. Since the normal function performs badly, Moody's uses its extensive data set on historic default frequencies to build an empirical distribution that maps the DD into a real default probability called Expected Default Frequency.

\subsubsection{Characteristics of the EDF sample}

Our EDF data is composed by daily 1-, 3- and 5-year EDFs for a sample of 95 firms and it covers from 01/Jun/2006 to 31/Mar/2010. This data has been provided by Moody's KMV. Table 4 displays summary statistics for the 1-year maturity.

\section{[INSERT TABLE 4 ABOUT HERE]}

By one side, the sector with less default likelihood is the Consumer Goods sector. For instance, an average Consumer Goods firm has a median default probability of 3.6 bps and low standard deviation with 7 bps. 
By the other side, Financial sector seems to exhibit higher default probabilities (in mean) than other sectors, with a mean of 22.2 bps and a standard deviation of $27.5 \mathrm{bps}$, probably due to the financial crisis period. Nevertheless, as we saw in a previous sections, Financial institutions are the ones with best quality ratings and the credit insurance market perceives them as one of the safest industries. It is also important to notice that all sectors but Financials showed a negative (although small) autocorrelation for the EDF changes, meaning that the EDFs tend to be revised up (down) if the previous day they were revised down (up). And the firms with higher default probability were the Industrials, with a median of 14.4 bps and standard deviation of 31.6 bps.

\subsection{Panel regressions between CDS and EDF}

Two approaches can be made if we want to measure the risk premium that investors are willing to pay in exchange for the risk they bear. The first method goes in line with Berndt et al. (2005) by performing panel regressions that capture the sensitivity of CDS spreads to default probabilities. The beta coefficients of the regressions represent the risk premium for bearing the default probability of a firm, and they are our target in this subsection. The second approach refers to Jarrow et al. (2005) and it is further implemented in Section 4. As we will see, it consists on measuring the credit event risk premium as the ratio of risk-neutral to real default intensities.

Table 5 provides the projections of 5-year CDS spreads onto the 5-year EDF. It is reasonable that protection buyers enter in a five year CDS contract to hedge against the default probability of a firm during the next five years. Then, it makes sense to regress CDS and EDF with the same maturity. Although some concerns about the effect of short term real default probabilities on CDS prices could be done, including 1-, 3- and 5year EDF maturities in the model provides no significant improvement in terms of variance explained. Thus, we only consider the 5-year EDF for illustration purposes.

\section{[INSERT TABLE 5 ABOUT HERE]}

Our estimations extend those of Berndt et al. (2005) in several aspects: firstly, since CDS spreads might not only include a default but also a liquidity compensation we account for the possible effects of liquidity on CDS spreads. Tang and Yan (2007) considers several liquidity proxies that generally depend on the bidask spread, volatility and inactivity of contracts. In practice, these measures make difficult to compare the 
liquidity across different periods and firms. As a possible solution we include the Fitch CDS Liquidity Score as a proxy for liquidity. The Fitch's scores depend on some liquidity variables previously mentioned and it represent the market's view of liquidity: the higher the score is, the more illiquid the CDS results. This score leads us to control for firm specific liquidity (LIQ5y) and average European CDS liquidity (LIQEU5y).

Additionally, we control for different stages of the crisis: when BNP freezes three funds and when the ECB increased the lending aid to financial institutions ${ }^{9}$. The selection of these two events attends to the highest increments in the 3-month Euribor-OIS spread. Thus, they are two potential dates for changes in corporate RP.

From inspection of Table 5, models V-VIII (log-log linear relationship between CDS and EDF) provide a better fit than models I-IV. These results are not surprising since the CDS and EDF data are highly positively skewed and non-normal, as deduced from summary statistics. These non-linearity component is consistent with Berndt et al. (2005) results for US market. Additionally, we wonder about unobservable factors that might be affecting the relationship between spreads and real default probabilities. For that reason, we introduce dummy variables in models III-IV and VII-VIII that account for fixed effects regarding different average rating, country, firm and sectors, respectively. Results seem to confirm that those dummies significantly improves the model Adj- $\mathrm{R}^{2}$ from $17 \%$ to $34 \%$ and from $52 \%$ to $71 \%$.

In model IV, dummies controlling for period reflect an increase during the crisis and a sensitivity reduction after ECB's announcement. Additionally, models II-IV and VI-VIII shows that investors entering in CDS contracts tend to pay higher spreads when individual CDS liquidity increases and/or market liquidity decreases (models IV and VIII).

In conclusion, it seems to be that the CDS spreads contain and a liquidity premium and a default risk premium that exhibits a non-linear, time varying behavior. With respect to the RP magnitudes, they seem to increase during the early stages of the crisis tending to diminish over time, possibly as a consequence of a generalized raising in actual probabilities.

\footnotetext{
${ }^{9}$ See the press release here: http://www.ecb.europa.eu/press/pr/date/2008/html/pr081008_2.en.html
} 


\section{Default risk premium}

This section presents the theoretical approach to the default risk premium implied by CDS. We adopt the double-stochastic Poisson framework of Duffie and Singleton (1999) or Lando (1998) for modeling default intensities. The discussion about risk premium is mainly taken from Jarrow et al. (2005).

\subsection{The model}

The double-stochastic Poisson modeling of Duffie and Singleton (1997) and Lando (1998) provides a tractable framework to measure the default risk premium embedded in CDS prices. Let us define $Q$ as the firm's survival probability under the actual measure $\mathbb{P}$ from current time $t$ to $T$, given that there is no default event before,

$$
Q\left(\tau>T \mid \mathscr{F}_{t}\right)=E_{t}^{\mathbb{P}}\left[e^{-\int_{t}^{T} \lambda_{s}^{\mathbb{P}} d s} \mid \mathscr{F}_{t}\right]
$$

where $\tau$ is the default time and $\lambda \Delta t$ is the average default intensity in a short time interval. In order to simplify things, we consider a risk premium setting consistent with Jarrow et al. (2005). We also assume a CIR model for the intensity process $\lambda_{t}^{\mathbb{P}}$ under the real measure $\mathbb{P}$

$$
d \lambda_{t}^{\mathbb{P}}=\kappa\left(\theta-\lambda_{t}^{\mathbb{P}}\right) d t+\sigma \sqrt{\lambda_{t}^{\mathbb{P}}} d B^{\mathbb{P}}
$$

with constant parameters for the long run mean $\kappa$, mean reversion rate $\theta$ and volatility $\sigma$ of the CIR process. By adopting this framework positiveness of intensity is ensured under certain regularity conditions. Moreover, standard results on affine processes (e.g. Duffie et al., 2000) lead to closed-form formulas to right-hand expression in (4), avoiding the problem of numerical differentiation.

Under the risk-neutral measure $Q$, two premiums arise to compensate investors: on the one hand, the drift adjustment $v$ from diffusive part, which prices the systematic risk factors that change the intensity process. On the other hand, the compensation for the default events $\mu$. This premium has been also referred in Driessen (2005) or Pan and Singleton (2006) and it is named default event risk premium, credit event risk premium or jump-to-default premium. The default event risk premium accounts for the premium needed to compensate 
the default event itself,

$$
d \lambda_{t}^{\mathbb{Q}}=(\kappa+v)\left(\frac{\mu \kappa \theta}{\kappa+v}-\lambda_{t}^{\mathbb{Q}}\right) d t+\sigma \sqrt{\mu \lambda_{t}^{\mathbb{Q}}} d B_{t}^{\mathbb{Q}}
$$

Within this framework, Yu (2002) provides a formula where the expected bond returns depend on the default event premium as the ratio of risk-neutral to real default intensity,

$$
\lambda^{\mathbb{Q}}=\mu \lambda^{\mathbb{P}}
$$

Expression (7) represents the compensation required for an investor to take on default risk and is the object of study in Berndt et al. (2005), Driessen (2005), Pan and Singleton (2006) and this paper. Its size and behavior have important implications for a bond holder. Under the conditionally diversifiable hypothesis of Jarrow et al. (2005), for a large portfolio of bonds the RP will only be diversified away if $\lambda^{\mathbb{P}}=\lambda \mathbb{Q}$, or equivalently if $\mu$ is equal to 1 . They explain the two reasons that could make this risk premium not to be diversified away: a low number of bonds in the portfolio, or that there exists the possibility that some firms default simultaneously.

One concern about the doubly stochastic assumption is that firm defaults are independent Poisson events, an assumption which has proven to be rejected in Das et al. (2007) since defaults tend to be clustered in certain periods of time. Although plausible, current literature on default risk (e.g. Pan and Singleton (2008) or Longstaff (2011)) tends to overlook this fact. Moreover, our estimation results in Section 5 seems to provide a high degree of accuracy in CDS spreads which may lead that independent assumption is not bad after all. Finally, the inclusion of a common factor is addressed in Berndt et al. (2005).

\subsection{Actual and risk-neutral intensities}

It follows from expression (7) that it is necessary the concurrence of actual and risk-neutral intensities for computing the default-event risk premium. Our strategy to estimate those intensities takes advantage of the closed-form expressions of the expectations under affine-form processes.

Concerning to the actual probabilities, we employ the EDF as a proper estimate of the actual default probabilities, an argument also employed by Berndt et al. (2005) or Pan and Singleton (2006). From the 
survival probability expression in (4),

$$
1-E D F(T)=E_{t}^{\mathbb{P}}\left[e^{-\int_{t}^{T} \lambda_{s}^{\mathbb{P}} d s} \mid \mathscr{F}_{t}\right]
$$

where $\mathrm{T}$ is equal to the maturity period in a Merton (1976) model.

On the other hand, risk-neutral intensities are taken from CDS data. Although some authors as Duffee (1999) or Driessen (2005) estimate the risk-neutral intensities from bond data, empirical evidence demonstrates that CDS spreads result in a more fresher set of information than bonds, see for instance, Blanco et al. (2005) or Forte and Peña (2009). Moreover, the absence of liquidity problems and a different tax treatment makes CDS spreads a proper measure for risk-neutral intensities (e.g. Liu et al., 2006).

To extract the information of risk-neutral probabilities, we employ the definition of the risk-neutral survival probability $Q$ at time $t$ over the next $T$ years in an inhomogeneous Poisson process

$$
p^{*}(t, T)=E_{t}^{\mathbb{Q}}\left[e^{-\int_{t}^{T} \lambda_{s}^{\mathbb{Q}} d s}\right]
$$

where $\lambda \mathbb{Q}$ is the risk-neutral default intensity and $p^{*}(t, T)$ is known in closed form for a CIR process. Then, the left-handed term in expression (1) is approximated as,

$$
\sum_{i=1}^{4 M} E_{t}^{\mathbb{Q}}\left[e^{-\int_{t}^{t+.25 i}\left(r_{s}+\lambda_{s}^{\mathbb{Q}}\right) d s}\right] \cong \sum_{i=1}^{4 M} D(t, t(i)) p^{*}(t, t(i))
$$

and the protection seller formula (right-hand term) results

$$
\begin{aligned}
L^{\mathbb{Q}} \int_{t}^{t+M} E_{t}^{\mathbb{Q}}\left[\lambda_{u}^{\mathbb{Q}} e^{-\int_{t}^{u}\left(r_{s}+\lambda_{s}^{\mathbb{Q}}\right) d s}\right] d u & \cong L^{\mathbb{Q}} \int_{t}^{t+M} D(t, u) E_{t}^{\mathbb{Q}}\left[-\frac{\partial}{\partial u} e^{-\int_{t}^{u} \lambda_{s}^{\mathbb{Q}} d s}\right] d u \\
& \cong L^{\mathbb{Q}} \sum_{i=1}^{4 M} D(t, t(i))\left[p^{*}(t, t(i))-p^{*}(t, t(i-1))\right]
\end{aligned}
$$

One problem that arises in practice is whether or not CDS spreads also contain a non-default component. In this case, our estimated ratio (7) would be a noisy estimate of the credit event risk premium that also includes a non-default component such as liquidity. Unfortunately, it is hardly difficult for us to disentangle whether the liquidity will cause an underestimation or an overestimation of the risk premium. Tang and Yan 
(2007) uses different proxies for liquidity and finds for monthly US data that on average, liquidity could account for about $20 \%$ of CDS spreads. Longstaff (2011) posits a reduced-form model for municipal debt where the intensity process captures default and liquidity (or a combination of both) risks. Finally, Bongaerts et al. (2010) builds an equilibrium asset pricing model with liquidity risk and finds empirically for expected returns on portfolios of US CDS contracts that the protection seller requires an expected liquidity premium. If this finding were to be true in Europe, our estimated ratio (7) would be overestimated. Still, this expected liquidity premium seems to be somewhat smaller for investment grade firms, which would alleviate the liquidity issue in our estimations.

Another possible bias in the estimation of the credit risk premium could arise by the fixed recovery rate assumption. Altman et al. (2005) finds empirically for high-yield US corporate bonds that aggregate historical default rates and empirical recovery rates are negatively correlated. This negative correlation might hide the fact that both variables vary with the business cycle. Bruche and González-Aguado (2010) tests a dynamic model where the business cycle affects default and recovery rates. They find that during upturns, the implied recovery rate of Senior Unsecured US bonds is $47 \%$ and during downturns is $32 \%$. And Schneider et al. (2009) reports a cross-section implied recovery of $79 \%$ with CDS on US Senior Unsecured Debt. Their estimates reflect the fact that sectors also play an important role because firms with tangible assets (Industrials and Utilities) have higher recovery rates than other sectors with more intangible assets (Consumer Goods and Financials).

In Europe, Moody's (2008) reports an historical recovery of a 54.9\% and 65.8\% during 2006 and 2007 -respectively- for European Senior Unsecured bonds. Markit has also provided us with daily estimated recoveries, summarized in Table 2 . The average recovery rate is $40 \%$, and it is not by chance. It is said in Markit (2009) that they generally "assume a 40\% recovery rate" for investment grade CDS, but "lower rated bonds are more dynamic and often reflect lower estimated recovery rates". In practice, we cannot be precise about the firm-specific time-variant recovery rate for investment grade firms. Then, we are conservative regarding the assumption of the recovery rate and go along with industry practice and with Berndt and Obreja (2010) assuming a recovery rate of $40 \%$ to price our investment-grade CDS. Needless to say, under this recovery assumption probably our risk premium estimate (7) would be underestimated, specially during times of low default rates and for traditional sectors with tangible assets. 


\section{Econometric framework and results}

This section presents the methodology to obtain the estimates of the default intensity process under real and risk-neutral measures, respectively. We also present our results about the default-event risk premium.

\subsection{Econometric framework and data}

Our sample consists on a comprehensive dataset of daily EDF probabilities and CDS spreads for a portfolio of 95 European firms across different sectors. We fully exploit the information implied in the default probability term structure of EDF and CDS by employing data with maturities 1-, 3- and 5-years. The sample period ranges from 01/Jun/2006 to 31/Mar/2010 and it covers the recent credit crisis right before the sovereign debt crisis in Europe. We also employ the 1-,3-,6-,9- and 12- months of Euribor rate and 2-, 3-, 4- and 5- year maturities of Euro-swap rate to construct the risk-free curve, similarly to US studies as Berndt et al. (2005). Intermediate periods have been bootstrapped from previous curve. EDF and CDS data are provided from Moody's and Markit, respectively. Euribor and swap rates are obtained from IHS Global Insight.

Our procedure consists on searching the best (in terms of mean squared error) set of intensity values and parameters that minimizes the distance between the theoretical default probabilities and their sample counterparts. This technique is known as the nonlinear least-squared regression and it is equivalent to a first stage of the Generalized Moments Method estimate of Hansen (1982). Actual default intensity estimates are obtained from matching the empirical default probabilities (measured by daily EDFs) and the theoretical default probabilities according to relationship in (8). The dynamics of $\lambda^{\mathbb{P}}$ are governed by the one-factor CIR model in (5). Similarly, our $\lambda \mathbb{Q}$ estimates are obtained from matching also the sample CDS spreads with theoretical ones. Theoretical spreads are generated by the risk-neutral intensity that equals the premium and

protection legs of the contract as specified in expressions (10-12). Finally, the dynamics of $\lambda \mathbb{Q}$ follows the one-factor CIR model in (6).

Then, we minimize the expression

$$
\min _{\lambda^{\mathbb{P}}, \lambda \mathbb{Q}} \sum_{t=1}^{T} \sum_{j=1}^{6}\left[s_{i j t}(M)-\hat{s}_{i j t}\left(\lambda_{i t}^{\mathbb{P}}, \lambda_{i t}^{\mathbb{Q}} ; \Theta\right)\right]^{2}
$$

where $s_{i j t}(M)$ denotes the six-vector of EDF and CDS spreads with maturities $M=1,3$ and 5 years for 
firm $i$, and $\hat{s}_{i j t}$ corresponds to the theoretical expressions of EDF and CDS in (8) and (10-12), respectively. $\Theta_{i}$ is the parameter vector $\Theta_{i}=(\kappa, \theta, \sigma, v)$. Parameter $\mu$ is computed as the ratio between $\lambda_{i t}^{\mathbb{Q}} / \lambda_{i t}^{\mathbb{P}}$. This estimation method has been employed in a similar context by Longstaff et al. (2005), Driessen (2005) or Longstaff and Rajan (2008). Finally, our procedure permits us to estimate jointly both actual and riskneutral intensities, avoiding the problem of different data frequency presented in the two-step procedure of Berndt et al. (2005). Concerned about whether the daily frequency is going to affect our estimations, we also estimate the default risk premium at weekly (Wednesday) and monthly (last Wednesday of each month) frequencies, but we basically obtain the same RP estimates as in the daily case.

\subsection{Results of RP across sectors and ratings}

Table 6 displays some results about the accuracy of our estimations. For the sake of brevity, the estimates of individual intensity processes are not reported but they are available upon request. Table 6 presents the projections of sample values onto fitted values of CDS and EDF data. Even a one-factor specification of the intensity process shows that the performance of the model in terms of $R^{2}$ is remarkably high, with $R^{2}$ terms of $80 \%$ and $76 \%$ on overall series of CDS and EDF increments. Additionally, the standard deviation of residuals is lower than 3bps for CDS and EDF cases.

\section{[INSERT TABLE 6 ABOUT HERE]}

A first intuition of the results is provided in Figure 1. This Figure depicts the evolution of the credit event risk premium along time for different quartiles (upper graph), ratings (medium graph) and some sectors (lower graph), respectively. Vertical bars denote the subsample periods. Firstly, it is clear that risk premium has increased substantially in August 2007 with respect to early dates, and suffers from the events during the financial crisis (such as the BNP Paribas freezing or the ECB's announcement). Secondly, risk premium exhibits a time-varying behavior across time also reported in Berndt et al. (2005). Thirdly, investors demand higher risk premiums to lower rating firms (medium graph), in median. Fourthly, we document that risk premiums differ across sectors (lower graph). Surprisingly to us, investors seem to demand lower risk premium to Financial sector than Basic or Consumer ones, at least for the European case. Finally, its clear that it exists a source of commonality in risk premium across sectors and across ratings. This fact is contradictory with the diversifiable hypothesis of Jarrow et al. (2005) and it might be indicating that an important fraction of 
systematic risk is being priced in the market.

\section{[INSERT FIGURE 1 ABOUT HERE]}

With regard to their magnitude, risk premium estimates are substantially higher than those previously reported in the literature. Table 7 details the averaged sample statistics for the risk premium across sectors, ratings and different subsamples. We see that the averaged median RP before BNP Paribas freezing is 23.81, and 41.74 for the entire period. These values differ substantially from previous estimates reported in the literature. For example Driessen (2005) reports estimates of risk premium around 2 for a weekly sample of US bonds from 1991 to 2000. Berndt et al. (2005) gets similar results for a CDS and EDF sample from 2000-2004, and Pan and Singleton (2006) reports risk premiums between 1 and 3 -and even less than onefor a short sample of Japanese banks. To our knowledge there is no other estimates of risk premium for US firms during more recent periods are available to us. Our results seems to evidence that the magnitude of risk premium is higher for the European than US case, specially during the recent financial events.

\section{[INSERT TABLE 7 ABOUT HERE]}

In general terms i) the RP increases substantially during the first period of the crisis (in mean and median terms); ii) RP exhibits higher volatility after 2007; iii) the higher and lower RPs correspond to Consumer Goods and Financial sectors, respectively and iv) RP is higher for lower credit ratings. To conclude, Table 7 seems to indicate that sector and rating matters on determining the size of risk premia. In this way, a portfolio of AA financial bonds might be considered as the actual proxy closest to the diversification hypothesis of Jarrow et al. (2005).

\subsection{Principal Components Analysis}

As previously mentioned, the joint behavior of the risk premia suggests the existence of different sources of commonality in the data. We explore this possibility by carrying out a Principal Component Analysis (PCA) onto the risk premium series, extending the analysis to our sample of CDS and EDF data. Table 8 resumes the explanatory power of first four principal components (PC) for risk premia, CDS spreads and EDF probabilities, respectively. To avoid the heterogeneity problem of level spread and volatility across firms, we study the standardized levels and first differences. 
Table 8 shows that an important source of commonality is behind risk premia. For example, just one factor explains about 56\% (20\%) of the joint variability in RP levels (increments), or around 70\% (27\%) if we include a second PC. A similar result has been reported by Berndt and Obreja (2010), where they obtain a first PC able to explain a 53\% of CDS returns across firms.

Concerning to the CDS spreads, we find a strong first principal component that drives its behavior (between $82 \%$ and $90 \%$ of variance explained) independently of the maturity. Those percentages diminish to a range between $30 \%-55 \%$ for changes in spreads, in line with some results for the US case. For example, Longstaff et al. (2008) also finds for the CDS spreads of firms included in the CDX index that the first component explains a $27 \%$ of the variation in 5-year CDS spreads. Finally, the existence of a dominant factor is also confirmed in the EDF sample with around 70\% (30\%) in levels (increments).

\section{[INSERT TABLE 8 ABOUT HERE]}

\section{Macroeconomic sources of risk premium}

This section assesses the macroeconomic drivers of the default risk premium. We proceed in two ways: at the individual level, we identify the variables affecting the individual risk premiums by performing a dynamic panel estimation. At the aggregate level, we analyze the dynamics of the first two principal components of risk premium by a Vector Autoregressive (VAR) approach.

\subsection{Variable description}

We focus on the possible sources affecting risk premium. Basically, our set of financial variables accounts for variables related to the sovereign risk, monetary policy, liquidity and equity market, respectively.

We are specially concerned about the public-to-private risk transfer in default risk premium. Dieckmann and Plank (2010) evidenced that Sovereign CDS spreads are sensitive to the health of the financial system, and argued that through this private-to-public risk transfer, the Sovereign CDS market incorporates possible financial industry bailouts. In the opposite direction, it has already been documented in Moody's (2009) that the presence of a sovereign crisis raises the corporate default rates. Thus, it seems reasonable that when sovereigns start to show difficulties, investors require a higher default risk premium for corporate debt. We will study whether the default risk premium required by corporate market participants is affected by the sovereign default risk. 
Then, we proxy for sovereign default risk through first (SOVPC1) and second (SOVPC2) principal components of 5-year sovereign CDS spreads. We employ the senior external contracts on fifteen Western European countries whose firms are included in the Markit database. Our available sample comprises contracts denominated in U.S. dollars under Old Restructuring clause. Table 9 provides some basic statistics and loadings of the first two principal components. Notice that first principal component is a weighted average of CDS spreads. It accounts for a 93\% of the total variation, similarly to other studies like Pan and Singleton (2008). Moving on the second component, it accounts for a 4,5\% of the variation and mainly assigns negative loadings to PIGS (Portugal, Italy, Greece and Spain) countries.

\section{[INSERT TABLE 9 ABOUT HERE]}

The monetary policy in EU targets a certain inflation rate. We select as proxies some financial variables that can be influenced by monetary authority decisions. Thus, the monetary policy is captured by the Euro overnight index average (EONIA), dollar-euro exchange rate (USD/EUR) and the slope (SLOPE) of the term structure. The slope is the difference between the 10-year and the 2-year yield of German bonds. Additionally, since the estimation of default risk premium is done with the Euribor-swap curve as risk-free rate, which is not totally default free, we employ the 3-month difference between the Euribor and the overnight interest swap (3M-EURIBOR-OIS) as a control variable.

Concerning to the variables representing the stock market we choose the Eurostoxx 50 Index (ESTOXX50) and the CBOE implied volatility index (VIX) in the next 30 days. We also control the influence of liquidity in risk premium by introducing the firm specific liquidity of the CDS contract (LIQ5y), the overall liquidity in the European market (LIQEU5y), and the Fitch 5-year Probability of Default Index for Western Europe (FPWE5y) as a measure of systemic risk.

Lastly, standard econometrics suggest that non-stationary time series regressions can lead to spurious relationships between variables because of common trends, even if they are not related at all. Table 10 shows results on a Augmented Dickey-Fuller and Phillis-Perron unit root tests. It turns out that all variables need a first difference in order to obtain a stationary time series. Therefore, we just consider the differenced variables. We also take logs of the positive variables to reduce the skewness of the variables.

[INSERT TABLE 10 ABOUT HERE] 


\subsection{Dynamic panel regression}

Table 11 shows different dynamic panel data regressions (of order one) for individual increments of risk premium versus the set of variables previously cited. Models I to III refer the different subsamples under study. Model IV comprises the entire period.

Model IV states that changes (in log) of risk premium are related negatively to changes (in log) of the stock market. In other words, negative stock returns are followed by increases in default risk premium. Furthermore, an appreciation of euro currency, a deterioration of systemic risk or an increase in the average sovereign CDS spread lead to higher default risk premium. In general, the stock and currency market factors were more significant for second and third subsamples (Models II and III). Instead, the systemic and sovereign factors were more relevant for the first subsample (Model I).

\section{[INSERT TABLE 11 ABOUT HERE]}

Interestingly enough, VIX is not a significant variable in general. Nor does the second component of sovereign spreads or liquidity variables. These results can result from the bias through high-quality firms used in our sample. Since the liquidity variables are not significant, it seems that our risk premium estimate can be called default risk premium after all.

In conclusion, higher investor compensation seem to derive from the general deterioration of market (stock, exchange, sovereign) conditions. Liquidity or monetary policy shocks might not affect risk premiums given the high-quality firms analyzed.

\subsection{Vector autoregressive model}

We turn next to the dynamic relationship of risk premium and financial variables at an aggregate level. Basically, we wonder about the impact of significant financial variables in previous section with the first two principal components of risk premium.

As a previous step of the analysis, Figure 2 plots the scores of first (RPPC1, upper graph) and second (RPPC2) components of risk premium with a market index (ESTOXX50) and the first component of sovereign spreads (SOVPC1), respectively. At a first glance, it seems to exist a negative correlation between stock market and first component of risk premium (upper graph) for second and third subsamples. Additionally, a 
negative relationship between second component or risk premium (lower graph) and the general level of CDS market appears during third subsample.

\section{[INSERT FIGURE 2 ABOUT HERE]}

It is time to quantify the relationship between the first two principal components of risk premium and the financial variables. We employ a vector autoregressive model (VAR) for the differenced variables. We estimate the VAR model for the most representative variables, i.e. the significant variables in the dynamic panel data model in Table 11. Our VAR model comprises until six lag variables according to the likelihood ratio test. Table 12 presents the results of Granger causality Wald tests. According to our results, the first principal component of risk premium increments is driven by market variables such a stock prices and exchange rates. On the other hand, second component is driven by the systemic risk within European firms and the default risk of European sovereign debt.

\section{[INSERT TABLE 12 ABOUT HERE]}

Once estimated the model, we build the Orthogonalized Impulse-Response Function (OIRF) for the principal components of the RP. Our purpose is to analyze how of shocks in certain variables are transferred to others. Figure 3 resumes our results. Upper graphs depict the response of principal component or risk premium to shocks in stock and exchange markets. Lower graphs plot the responses of second principal component of risk premium to changes in systemic risk proxy and first component of sovereign spreads, respectively. In general, shocks in the impulse variables produces responses that fade away in short periods of time, usually before five days. With regard to the results, only changes in stock or exchange markets produce significant responses in the first component of risk premium. In general, positive shocks in stock (exchange) markets lead to significant decrease (increase) in risk premium changes. Additionally, changes on systemic risk and overall sovereign risk produce significant changes in second component of risk premium during the following days.

\section{[INSERT FIGURE 3 ABOUT HERE]}

In conclusion, it seems that first component of changes in risk premium is affected by movements in stock and exchange markets. Second component appears to price the some sort of credit/systemic risk in the economy. 


\section{Conclusions}

This article has focused on the default risk premium embedded in European CDS spreads. We address the behavior of the risk premium for a sample of European firms during years 2006-2010, a period which includes the recent financial crisis. We employ the information contained in default swaps and KMV Moody's default probabilities to learn about how investors are assessing the risk of changes in bond prices under default circumstances.

From an empirical point of view, we have examined the risk premium in several directions: firstly, we perform a panel data analysis to capture the relationship between risk-neutral (CDS spreads) and actual (EDF) values. Secondly, we analyze the risk premium under the framework of double-stochastic processes of Duffie and Singleton $(1997,1999)$ in order to explore the presence of common factors across firms that affect the default premiums. Thirdly, we measure a dynamic panel data model to identify the significant variables that affect the firm specific risk premium. Finally, we carry out a VAR model to analyze which financial or macro variables drive this co-movement through time.

Our results show a strong relationship between actual and default probabilities. Our findings seem to confirm a time varying behavior of risk premium. Additionally, the median size of risk premium is about 40 during our sample period. These values are significantly higher that those previously reported in the literature by Driessen (2005) or Berndt et al. (2005) for US firms. We also report a dominant source of commonality on risk premiums that accounts for the $60 \%$ of the total variability. Panel regressions and VAR model analysis suggest a link between market variables (stock prices, exchange rates) and the first principal component of risk premiums. Additionally, empirical evidence indicate a public-to-private risk transfer between the sovereign CDS and corporate risk premium. Finally, our risk premium measurements are not affected by the liquidity of the CDS market and could be considered as default risk premium.

In conclusion, this paper has studied empirically the size and behavior of default risk event premium for a sample of European firms, analyzing the presence of common factors across firms that might affect those default premiums and which portion of this co-movement is attributable to financial or macro variables. These results might have important implications for risk management and portfolio allocation strategies. 


\section{References}

Altman, E. I., Brady, B. and Resti, A. (2005), 'The link between default and recovery rates: theory, empirical evidence, and implications', The Journal of Business 78(6), 2203-2227.

Bedendo, M., Cathcart, L. and El-Jahel, L. (2009), 'Market and model credit default swap spreads: mind the gap!', European Financial Management .

Berndt, A., Douglas, R., Duffie, D., Ferguson, M. and Schranz, D. (2005), Measuring default risk premia from default swap rates and EDFs. Working Paper.

Berndt, A. and Obreja, I. (2010), 'Decomposing european CDS returns', Review of Finance 14(2), 1-45.

Bharath, S. T. and Shumway, T. (2008), 'Forecasting default with the merton distance to default model', The Review of Financial Studies 21(3), 1339-1369.

Blanco, R., Brennan, S. and Marsh, I. W. (2005), 'An empirical analysis of the dynamic relation between investment-grade bonds and credit default swaps', The Journal of Finance 60(5), 2255-2281.

Bongaerts, D., Jong, F. D. and Driessen, J. (2010), Derivative pricing with liquidity risk: theory and evidence from the credit default swap market. Forthcoming in The Journal of Finance.

Bruche, M. and González-Aguado, C. (2010), 'Recovery rates, default probabilities, and the credit cycle', Journal of Banking \& Finance 34(4), 754-764.

Chen, R.-R., Cheng, X. and Wu, L. (2005), Dynamic interactions between interest rate, credit, and liquidity risks: theory and evidence from the term structure of credit default swap spreads. Working Paper.

Cremers, K. J. M., Driessen, J. and Maenhout, P. (2008), 'Explaining the level of credit spreads: optionimplied jump risk premia in a firm value model', The Review of Financial Studies 21(5), 2209-2242.

Crosbie, P. and Bohn, J. (2003), Modeling default risk. Available at: http://www.moodyskmv.com/research/files/wp/ModelingDef aultRisk.pdf.

Das, S. R., Duffie, D., Kapadia, N. and Saita, L. (2007), 'Common failings: How corporate defaults are correlated', The Journal of Finance 62(1), 93-118. 
Das, S. R. and Hanouna, P. (2009), 'Hedging credit: equity liquidity matters', Journal of Financial Intermediation 18(1), 112-123.

Dieckmann, S. and Plank, T. (2010), Default risk of advanced economies: an empirical analysis of credit default swaps during the financial crisis. Working Paper.

Driessen, J. (2005), 'Is default event risk priced in corporate bonds?', The Review of Financial Studies 18(1), 165-195.

Duffee, G. R. (1999), 'Estimating the price of default risk', The Review of Financial Studies 12(1), 197-226.

Duffie, D., Pan, J. and Singleton, K. (2000), 'Transform analysis and asset pricing for affine jump-diffusions', Econometrica 68(6), 1343-1376.

Duffie, D. and Singleton, K. J. (1997), 'An econometric model of the term structure of interest-rate swap yields', The Journal of Finance 52(4), 1287-1321.

Duffie, D. and Singleton, K. J. (1999), 'Modeling term structures of defaultable bonds', The Review of Financial Studies 12(4), 687-720.

Dwyer, D. and Qu, S. (2007), EDF 8.0 model enhancements. Available at: http://www.moodyskmv.com/products/files/EDF8_Model_Enhancements.pdf.

ECB (2009), Credit default swaps and counterparty risk. Available at http://www.ecb.int/pub/pdf/other/creditdefaultswapsandcounterpartyrisk2009en.pdf.

Ericsson, J., Jacobs, K. and Oviedo, R. (2009), 'The determinants of credit default swap premia', Journal of Financial and Quantitative Analysis 44(1), 109-132.

Forte, S. and Peña, J. I. (2009), 'Credit spreads: An empirical analysis on the informational content of stocks, bonds, and CDS', Journal of Banking \& Finance 33(11), 2013-2025.

Hansen, L. P. (1982), 'Large sample properties of generalized method of moments estimators', Econometrica 50(4), 1029-1054. 
Jarrow, R. A., Lando, D. and Yu, F. (2005), 'Default risk and diversification: theory and empirical implications', Mathematical Finance 15(1), 1-26.

Kealhofer, S. (2003), 'Quantifying credit risk I: default prediction', Financial Analysts Journal 59(1), 30-44.

Korablev, I. and Dwyer, D. (2007), Power and level validation of moody's kmv $\mathrm{EDF}^{T M}$ credit measures in north america, europe, and asia. Available at: http://www.moodyskmv.com/research/files/wp/EDF_Validation_All_2007.pdf.

Lando, D. (1998), 'On Cox processes and credit risky securities', Review of Derivatives Research 2, 99-120.

Liu, J., Longstaff, F. A. and Mandell, R. E. (2006), 'The market price of risk in interest rate swaps: the roles of default and liquidity risks', Journal of Business 79(5), 2337-2359.

Longstaff, F. A. (2011), 'Municipal debt and marginal tax rates: Is there a tax premium in asset prices?', The Journal of Finance .

Longstaff, F. A., Mithal, S. and Neis, E. (2005), 'Corporate yield spreads: Default risk or liquidity? new evidence from the credit default swap market', The Journal of Finance 60(5), 2213-2253.

Longstaff, F. A., Pan, J., Pedersen, L. H. and Singleton, K. J. (2008), How sovereign is sovereign credit risk? Working Paper.

Longstaff, F. A. and Rajan, A. (2008), 'An empirical analysis of the pricing of collateralized debt obligations', The Journal of Finance 63(2), 529-563.

Markit (2009), Markit credit indices: a primer.

Merton, R. C. (1974), 'On the pricing of corporate debt: the risk structure of interest rates', The Journal of Finance 29(2), 449-470.

Moody’s (2008), European corporate default and recovery rates, 1985-2007. Moody’s Global Credit Research.

Moody's (2009), Emerging market corporate and sub-sovereign defaults and sovereign crises: perspectives on country risk. Moody’s Global Credit Research. 
Pan, J. and Singleton, K. J. (2006), 'Interpreting recent changes in the credit spreads of Japanese banks', Monetary and Economic Studies pp. 129-150.

Pan, J. U. N. and Singleton, K. J. (2008), 'Default and recovery implicit in the term structure of sovereign CDS spreads', The Journal of Finance 63(5), 2345-2384.

Petersen, M. A. (2009), 'Estimating standard errors in finance panel data sets: comparing approaches', The Review of Financial Studies 22(1), 435-480.

Schneider, P., Sögner, L. and Veza, T. (2009), The economic role of jumps and recovery rates in the market for corporate default risk. Journal of Financial and Quantitative Analysis, Forthcoming.

Tang, D. Y. and Yan, H. (2007), Liquidity and credit default swap spreads. Working Paper.

Vassalou, M. and Xing, Y. (2004), 'Default risk in equity returns', The Journal of Finance 59(2), 831-868.

Yu, F. (2002), Modeling expected return on defaultable bonds. Working Paper.

Zhang, B. Y., Zhou, H. and Zhu, H. (2009), 'Explaining credit default swap spreads with equity volatility and jump risks of individual firms', The Review of Financial Studies 22(12), 5099-5131. 


\section{Tables}

Table 1: Distribution of firms across sectors, average ratings and countries

\begin{tabular}{lcccccccccrr}
\hline \hline & BM & CG & CS & Fin & HC & Ind & OG & Tech & TC & Util & Total \\
\hline \multicolumn{8}{c}{ Panel A.- Av. Rating AA } \\
France & 0 & 0 & 0 & 3 & 0 & 0 & 1 & 0 & 0 & 1 & 5 \\
Germany & 0 & 0 & 0 & 1 & 0 & 0 & 0 & 0 & 0 & 0 & 1 \\
Italy & 0 & 0 & 0 & 1 & 0 & 0 & 0 & 0 & 0 & 0 & 1 \\
Spain & 0 & 0 & 0 & 1 & 0 & 0 & 0 & 0 & 0 & 0 & 1 \\
Switzerland & 0 & 1 & 0 & 0 & 0 & 0 & 0 & 0 & 0 & 0 & 1 \\
United Kingdom & 0 & 0 & 0 & 1 & 0 & 0 & 0 & 0 & 0 & 0 & 1 \\
Total & 0 & 1 & 0 & 7 & 0 & 0 & 1 & 0 & 0 & 1 & 10
\end{tabular}

Panel B.- Av. Rating A

$\begin{array}{lllllllllllr}\text { Finland } & 0 & 0 & 0 & 0 & 0 & 0 & 0 & 0 & 0 & 1 & 1 \\ \text { France } & 0 & 0 & 1 & 1 & 0 & 0 & 0 & 0 & 1 & 1 & 4 \\ \text { Germany } & 1 & 2 & 0 & 2 & 1 & 1 & 0 & 0 & 0 & 3 & 10 \\ \text { Italy } & 0 & 0 & 0 & 1 & 0 & 0 & 0 & 0 & 0 & 1 & 2 \\ \text { Netherlands } & 1 & 2 & 0 & 1 & 0 & 1 & 0 & 0 & 0 & 0 & 5 \\ \text { Norway } & 0 & 0 & 0 & 0 & 0 & 0 & 0 & 0 & 1 & 0 & 1 \\ \text { Portugal } & 0 & 0 & 0 & 1 & 0 & 0 & 0 & 0 & 0 & 1 & 2 \\ \text { Spain } & 0 & 0 & 0 & 0 & 0 & 0 & 0 & 0 & 0 & 1 & 1 \\ \text { Sweden } & 0 & 0 & 0 & 0 & 0 & 0 & 0 & 0 & 1 & 0 & 1 \\ \text { United Kingdom } & 0 & 1 & 1 & 2 & 0 & 1 & 1 & 0 & 0 & 2 & 8 \\ \text { Total } & 2 & 5 & 2 & 8 & 1 & 3 & 1 & 0 & 3 & 10 & 35\end{array}$

\section{Panel C.- Av. Rating BBB}

$\begin{array}{lllllllllllr}\text { Austria } & 0 & 0 & 0 & 0 & 0 & 0 & 0 & 0 & 1 & 0 & 1 \\ \text { France } & 0 & 1 & 4 & 0 & 0 & 3 & 1 & 0 & 1 & 0 & 10 \\ \text { Germany } & 1 & 1 & 1 & 0 & 0 & 1 & 0 & 0 & 1 & 0 & 5 \\ \text { Greece } & 0 & 0 & 0 & 0 & 0 & 0 & 0 & 0 & 1 & 0 & 1 \\ \text { Italy } & 0 & 0 & 0 & 0 & 0 & 1 & 0 & 0 & 1 & 1 & 3 \\ \text { Netherlands } & 1 & 0 & 2 & 0 & 0 & 1 & 0 & 1 & 1 & 0 & 6 \\ \text { Spain } & 0 & 0 & 0 & 0 & 0 & 0 & 1 & 0 & 1 & 1 & 3 \\ \text { Sweden } & 0 & 2 & 0 & 0 & 0 & 1 & 0 & 0 & 0 & 0 & 3 \\ \text { Switzerland } & 0 & 0 & 0 & 1 & 0 & 2 & 0 & 0 & 0 & 0 & 3 \\ \text { United Kingdom } & 2 & 2 & 7 & 0 & 0 & 1 & 0 & 0 & 2 & 1 & 15 \\ \text { Total } & 4 & 6 & 14 & 1 & 0 & 10 & 2 & 1 & 9 & 3 & 50\end{array}$

Panel D.- All Av. Ratings

\begin{tabular}{llllllllllll} 
Total & 6 & 12 & 16 & 16 & 1 & 13 & 4 & 1 & 12 & 14 & 95 \\
\hline
\end{tabular}

This table shows the distribution of firms across different sectors, average ratings and countries. Average ratings vary from AA to BBB. Sectors correspond to Basic Materials (BM), Consumer Goods (CG), Consumer Services (CS), Financial (Fin), Health Care (HC), Industrials (Ind), Oil \& Gas (OG), Technological (Tech), Telecommunications (TC) and Utilities (Util). 
Table 2: Summary Statistics of the CDS5y spreads

\begin{tabular}{|c|c|c|c|c|c|c|c|c|c|c|c|c|c|c|}
\hline & $\begin{array}{r}\text { Mean } \\
(\mathrm{bps})\end{array}$ & $\begin{array}{r}\text { Median } \\
(\mathrm{bps}) \\
\end{array}$ & $\begin{array}{r}\text { Std } \\
(\mathrm{bps}) \\
\end{array}$ & Skew & Kurt & $\begin{array}{r}\text { Min } \\
\text { (bps) }\end{array}$ & $\begin{array}{r}\text { Max } \\
\text { (bps) }\end{array}$ & $\begin{array}{r}\overline{\Delta s} \\
\text { (bps) }\end{array}$ & $\begin{array}{r}\text { Acorr }(\Delta s) \\
(1 \mathrm{st} \text { lag }) \\
\end{array}$ & $\begin{array}{r}\text { Recovery } \\
(\%) \\
\end{array}$ & Obs & $\begin{array}{r}\text { Longest Miss } \\
\text { (Days) }\end{array}$ & $\begin{array}{r}\text { Miss } \\
(\%) \\
\end{array}$ & $\begin{array}{r}\text { Zero inc. } \\
(\%)\end{array}$ \\
\hline \multicolumn{15}{|c|}{ Panel A.- Basic Materials } \\
\hline Mean & 112.06 & 79.12 & 110.50 & 1.55 & 5.35 & 21.54 & 575.62 & 0.0427 & 0.3177 & 40.00 & 1000 & 0.00 & 0.00 & 2.20 \\
\hline Std & 72.93 & 34.24 & 117.54 & 0.51 & 1.98 & 8.16 & 620.47 & 0.0316 & 0.0385 & 0.00 & 0 & 0.00 & 0.00 & 1.17 \\
\hline Min & 53.08 & 46.60 & 28.14 & 1.04 & 3.47 & 13.51 & 146.67 & 0.0029 & 0.2629 & 40.00 & 1000 & 0.00 & 0.00 & 1.30 \\
\hline $\operatorname{Max}$ & 239.84 & 126.58 & 325.24 & 2.40 & 8.70 & 35.87 & 1725.66 & 0.0896 & 0.3662 & 40.00 & 1000 & 0.00 & 0.00 & 4.50 \\
\hline \multicolumn{15}{|c|}{ Panel B.- Consumer Goods } \\
\hline Mean & 68.19 & 62.56 & 48.51 & 0.90 & 3.34 & 15.22 & 234.88 & 0.0411 & 0.2260 & 40.00 & 999 & 2.00 & 0.10 & 3.11 \\
\hline Std & 25.15 & 20.03 & 27.74 & 0.44 & 1.10 & 6.38 & 134.50 & 0.0171 & 0.0883 & 0.00 & 1 & 0.00 & 0.10 & 2.15 \\
\hline Min & 32.23 & 30.32 & 16.33 & 0.22 & 2.02 & 3.00 & 87.85 & 0.0183 & 0.0145 & 40.00 & 998 & 2.00 & 0.00 & 1.80 \\
\hline Max & 103.34 & 89.98 & 110.34 & 1.56 & 5.18 & 25.13 & 523.48 & 0.0729 & 0.3213 & 40.00 & 1000 & 2.00 & 0.20 & 9.30 \\
\hline \multicolumn{15}{|c|}{ Panel C.- Consumer Services } \\
\hline Mean & 98.09 & 82.83 & 67.98 & 1.24 & 4.69 & 24.79 & 341.86 & 0.0432 & 0.2392 & 40.00 & 999 & 2.00 & 0.09 & 2.26 \\
\hline Std & 42.41 & 31.42 & 44.19 & 0.60 & 2.56 & 9.82 & 180.70 & 0.0393 & 0.0492 & 0.00 & 1 & 0.00 & 0.10 & 1.53 \\
\hline Min & 46.46 & 46.13 & 17.05 & 0.53 & 2.33 & 7.42 & 125.88 & -0.0483 & 0.1366 & 40.00 & 998 & 2.00 & 0.00 & 0.90 \\
\hline $\operatorname{Max}$ & 192.80 & 141.98 & 169.38 & 2.68 & 11.45 & 41.60 & 734.79 & 0.0935 & 0.3271 & 40.00 & 1000 & 2.00 & 0.20 & 7.40 \\
\hline \multicolumn{15}{|c|}{ Panel D.- Financials } \\
\hline Mean & 72.13 & 73.83 & 56.70 & 0.46 & 2.58 & 6.69 & 254.60 & 0.0852 & 0.2408 & 40.00 & 1000 & 2.00 & 0.01 & 3.97 \\
\hline Std & 22.64 & 17.43 & 26.64 & 0.42 & 0.90 & 1.66 & 133.23 & 0.0315 & 0.0433 & 0.00 & 1 & 0.00 & 0.05 & 1.56 \\
\hline Min & 44.29 & 47.79 & 30.46 & -0.05 & 1.58 & 3.97 & 136.30 & 0.0516 & 0.1733 & 40.00 & 998 & 2.00 & 0.00 & 2.10 \\
\hline $\operatorname{Max}$ & 134.77 & 118.93 & 130.39 & 1.33 & 5.01 & 8.92 & 588.30 & 0.1726 & 0.3104 & 40.00 & 1000 & 2.00 & 0.20 & 7.40 \\
\hline \multicolumn{15}{|c|}{ Panel E.- Industrials } \\
\hline Mean & 96.10 & 78.60 & 81.48 & 1.42 & 5.37 & 17.98 & 411.00 & 0.0610 & 0.3267 & 40.00 & 999 & 2.00 & 0.08 & 2.40 \\
\hline Std & 39.37 & 23.93 & 49.71 & 0.70 & 2.86 & 4.49 & 220.21 & 0.0352 & 0.0808 & 0.00 & 1 & 0.00 & 0.11 & 0.76 \\
\hline Min & 44.42 & 43.45 & 21.94 & 0.19 & 1.79 & 9.96 & 105.76 & 0.0192 & 0.1743 & 40.00 & 997 & 2.00 & 0.00 & 1.70 \\
\hline Max & 167.80 & 114.34 & 192.12 & 2.34 & 11.00 & 25.00 & 904.33 & 0.1561 & 0.4489 & 40.00 & 1000 & 2.00 & 0.30 & 4.50 \\
\hline \multicolumn{15}{|c|}{ Panel F.- Telecommunications } \\
\hline Mean & 79.90 & 73.00 & 45.21 & 0.85 & 3.16 & 23.81 & 228.25 & 0.0394 & 0.2293 & 40.00 & 999 & 2.00 & 0.08 & 1.75 \\
\hline$S t d$ & 23.14 & 22.07 & 21.76 & 0.26 & 0.69 & 6.06 & 89.54 & 0.0311 & 0.0492 & 0.00 & 1 & 0.00 & 0.10 & 0.33 \\
\hline Min & 56.27 & 45.67 & 25.26 & 0.52 & 2.27 & 16.44 & 137.55 & -0.0168 & 0.1557 & 40.00 & 998 & 2.00 & 0.00 & 1.30 \\
\hline Max & 141.31 & 120.78 & 105.92 & 1.34 & 4.19 & 32.82 & 467.94 & 0.1015 & 0.3201 & 40.00 & 1000 & 2.00 & 0.20 & 2.20 \\
\hline \multicolumn{15}{|c|}{ Panel G.- Utilities } \\
\hline Mean & 62.53 & 54.18 & 47.72 & 0.90 & 3.50 & 10.91 & 225.11 & 0.0530 & 0.2348 & 40.00 & 1000 & 2.00 & 0.04 & 2.30 \\
\hline$S t d$ & 21.13 & 12.27 & 30.81 & 0.53 & 1.44 & 3.83 & 145.16 & 0.0245 & 0.0606 & 0.00 & 1 & 0.00 & 0.09 & 0.77 \\
\hline Min & 38.02 & 38.59 & 20.81 & 0.12 & 2.01 & 5.25 & 93.08 & 0.0196 & 0.1409 & 40.00 & 998 & 2.00 & 0.00 & 1.60 \\
\hline $\operatorname{Max}$ & 110.23 & 79.95 & 131.20 & 2.25 & 7.74 & 17.84 & 630.77 & 0.1041 & 0.4014 & 40.00 & 1000 & 2.00 & 0.20 & 4.60 \\
\hline \multicolumn{15}{|c|}{ Panel H.- Others (Health Care, Oil and Gas, and Technology) } \\
\hline Mean & 63.31 & 52.03 & 52.22 & 1.41 & 4.89 & 13.61 & 253.66 & 0.0373 & 0.2588 & 40.00 & 999 & 2.00 & 0.13 & 2.93 \\
\hline$S t d$ & 28.22 & 16.18 & 29.96 & 0.56 & 1.73 & 7.26 & 145.80 & 0.0205 & 0.0563 & 0.00 & 1 & 0.00 & 0.10 & 1.56 \\
\hline Min & 31.15 & 33.97 & 24.12 & 0.57 & 2.59 & 3.78 & 103.22 & 0.0104 & 0.1823 & 40.00 & 998 & 2.00 & 0.00 & 1.60 \\
\hline $\operatorname{Max}$ & 103.94 & 76.44 & 97.55 & 2.07 & 7.24 & 20.48 & 487.50 & 0.0724 & 0.3150 & 40.00 & 1000 & 2.00 & 0.20 & 5.80 \\
\hline \multicolumn{15}{|c|}{ Panel I.- OVERALL } \\
\hline Mean & 80.82 & 70.53 & 61.30 & 1.02 & 3.94 & 16.52 & 300.75 & 0.0530 & 0.2541 & 40.00 & 999 & 2.00 & 0.07 & 2.65 \\
\hline$S t d$ & 36.59 & 24.33 & 45.92 & 0.60 & 2.03 & 8.84 & 226.24 & 0.0337 & 0.0690 & 0.00 & 1 & 0.00 & 0.10 & 1.47 \\
\hline Min & 31.15 & 30.32 & 16.33 & -0.05 & 1.58 & 3.00 & 87.85 & -0.0483 & 0.0145 & 40.00 & 997 & 2.00 & 0.00 & 0.90 \\
\hline $\operatorname{Max}$ & 239.84 & 141.98 & 325.24 & 2.68 & 11.45 & 41.60 & 1725.66 & 0.1726 & 0.4489 & 40.00 & 1000 & 2.00 & 0.30 & 9.30 \\
\hline
\end{tabular}

This Table includes a summary of the main statistics for the 5-year CDS spreads: the mean, median, standard deviation, skewness, kurtosis, minimum, maximum, mean of the differenced spreads, 1st lag autocorrelation coefficient for the differenced spreads, mean recovery, number of observations, longest series of consecutive missing spreads, percentage of missing values, and percentage of days with zero increment over the previous day. Our sample consists of daily CDS spreads for 95 European firms included in the Markit's database, covering from 01/Jun/2006 to 31/Mar/2010. 
Table 3: Test statistics for different groups of CDS5y

\begin{tabular}{|c|c|c|c|c|c|c|c|c|c|c|c|}
\hline & \multirow[b]{2}{*}{ All } & \multicolumn{2}{|c|}{ Av. Rating } & \multicolumn{2}{|c|}{ Regions } & \multicolumn{4}{|c|}{ Sectors } & \multicolumn{2}{|c|}{ Time (09/Aug/2007) } \\
\hline & & AA-A & BBB & PIGS & NonPIGS & Cmdty & NonCmdty & Fin & NonFin & Before & After \\
\hline & \multicolumn{11}{|c|}{ Panel A.- Spreads $(s)$} \\
\hline Obs. & 94937 & $47.38 \%$ & $52.61 \%$ & $8.42 \%$ & $91.58 \%$ & $25.26 \%$ & $74.73 \%$ & $16.85 \%$ & $83.14 \%$ & $31.02 \%$ & $68.97 \%$ \\
\hline Mean & 80.814 & 63.294 & 96.591 & 78.058 & 81.067 & 75.275 & 82.686 & 72.125 & 82.575 & 25.981 & 105.472 \\
\hline Median & 59.692 & 50.512 & 69.197 & 70.453 & 59.000 & 51.691 & 62.789 & 65.475 & 58.556 & 23.212 & 81.679 \\
\hline WMW & & \multicolumn{2}{|c|}{$(0.000)$} & \multicolumn{2}{|c|}{$(0.239)$} & \multicolumn{2}{|c|}{$(0.000)$} & \multicolumn{2}{|c|}{$(0.000)$} & \multicolumn{2}{|c|}{$(0.000)$} \\
\hline Std. & 84.630 & 59.454 & 99.517 & 64.218 & 86.260 & 102.123 & 77.743 & 66.014 & 87.819 & 17.441 & 91.029 \\
\hline $\mathrm{AB}$ & & \multicolumn{2}{|c|}{$(0.000)$} & \multicolumn{2}{|c|}{$(0.000)$} & \multicolumn{2}{|c|}{$(0.000)$} & \multicolumn{2}{|c|}{$(0.000)$} & \multicolumn{2}{|c|}{$(0.000)$} \\
\hline & \multicolumn{11}{|c|}{ Panel B.- Spread changes $(\Delta s)$} \\
\hline Obs. & 94810 & $47.39 \%$ & $52.60 \%$ & $8.42 \%$ & $91.58 \%$ & $25.26 \%$ & $74.73 \%$ & $16.85 \%$ & $83.14 \%$ & $30.96 \%$ & $69.03 \%$ \\
\hline Mean & 0.053 & 0.055 & 0.051 & 0.088 & 0.050 & 0.050 & 0.054 & 0.086 & 0.047 & 0.028 & 0.065 \\
\hline Median & -0.004 & 0.000 & -0.019 & 0.000 & -0.005 & -0.012 & -0.002 & 0.000 & -0.016 & -0.015 & 0.000 \\
\hline WMW & & \multicolumn{2}{|c|}{$(0.000)$} & \multicolumn{2}{|c|}{$(0.198)$} & \multicolumn{2}{|c|}{$(0.128)$} & \multicolumn{2}{|c|}{$(0.000)$} & \multicolumn{2}{|c|}{$(0.498)$} \\
\hline Std. & 5.503 & 4.578 & 6.220 & 4.976 & 5.549 & 5.934 & 5.350 & 5.873 & 5.425 & 1.458 & 6.551 \\
\hline $\mathrm{AB}$ & & \multicolumn{2}{|c|}{$(0.000)$} & \multicolumn{2}{|c|}{$(0.000)$} & \multicolumn{2}{|c|}{$(0.000)$} & \multicolumn{2}{|c|}{$(0.000)$} & \multicolumn{2}{|c|}{$(0.000)$} \\
\hline
\end{tabular}

This Table includes summary statistics for several groups of spreads in basis points (mean, median and standard deviation) and the main test statistics for those groups: higher investment grade (from AA to A) vs. lower investment grade (BBB), PIGS (Portugal, Ireland, Greece and Spain) vs. non PIGS, commodity vs. non commodity, financials vs. nonfinancials, and before vs. after BNP Paribas froze three investment funds in 09/Aug/2007. Cmdty group includes firms from Basic Materials, Oil \& Gas and Utility sectors. Mean, median and standard deviation are provided in basis points. We performed the Jarque-Bera (JB) normality test, rejecting the null hypothesis at $1 \%$ significance level for every group. As normality assumption is dropped and therefore a parametric t-test is not feasible, we perform several nonparametric two-sample tests of location-scale (KS), location (WMW) and scale (AB). The two-sample Kolmogorov-Smirnov (KS) goodness-of-fit measure tests the null hypothesis that both groups come from the same continuous distribution. Results rejected the null hypothesis at $10 \%$ significance level for the first difference of spreads separated by PIGS and NonPIGS; and at $1 \%$ level for the rest of the groups. The Ansari-Bradley (AB) test is performed after subtracting the median to each group under the null hypothesis of equal variances. The Wilcoxon-Mann-Whitney (WMW) test performs the null hypothesis that both groups have equal medians, but this statistic requires equal dispersions of both groups, and shouldn't be taken into account if the $\mathrm{AB}$ test rejects the hypothesis of equal variances. JB and KS tests are available upon request. 
Table 4: Summary Statistics of the EDF1y

\begin{tabular}{|c|c|c|c|c|c|c|c|c|c|c|c|c|c|}
\hline Firm & $\begin{array}{r}\text { Mean } \\
\text { (bps) }\end{array}$ & $\begin{array}{r}\text { Median } \\
\text { (bps) }\end{array}$ & $\begin{array}{r}\text { Std } \\
\text { (bps) }\end{array}$ & Skew & Kurt & $\begin{array}{r}\text { Min } \\
(\mathrm{bps})\end{array}$ & $\begin{array}{r}\text { Max } \\
\text { (bps) }\end{array}$ & $\begin{array}{r}\overline{\Delta s} \\
\text { (bps) }\end{array}$ & $\begin{array}{r}\operatorname{Acorr}(\Delta s) \\
(1 \mathrm{st} \text { lag }) \\
\end{array}$ & Obs & $\begin{array}{r}\text { Longest Miss } \\
\text { (Days) }\end{array}$ & $\begin{array}{r}\text { Miss } \\
(\%)\end{array}$ & $\begin{array}{r}\text { Zero inc. } \\
(\%)\end{array}$ \\
\hline \multicolumn{14}{|c|}{ Panel A.- Basic Materials } \\
\hline Mean & 13.50 & 3.80 & 27.86 & 2.02 & 12.60 & 1.23 & 242.47 & 0.0062 & -0.0227 & 974 & 2.33 & 2.57 & 11.10 \\
\hline Std & 13.00 & 1.42 & 46.68 & 2.64 & 24.00 & 0.36 & 506.88 & 0.0045 & 0.0596 & 4 & 0.52 & 0.37 & 13.27 \\
\hline $\operatorname{Min}$ & 2.40 & 1.40 & 1.56 & 0.51 & 1.55 & 1.00 & 5.76 & 0.0000 & -0.1304 & 971 & 2.00 & 2.10 & 2.30 \\
\hline $\operatorname{Max}$ & 37.29 & 5.59 & 121.93 & 7.32 & 61.51 & 1.80 & 1275.52 & 0.0136 & 0.0343 & 979 & 3.00 & 2.90 & 37.50 \\
\hline \multicolumn{14}{|c|}{ Panel B.- Consumer Goods } \\
\hline Mean & 6.14 & 3.63 & 7.05 & 1.11 & 5.41 & 1.35 & 33.68 & 0.0187 & -0.0318 & 971 & 2.50 & 2.91 & 40.79 \\
\hline Std & 8.41 & 3.86 & 17.36 & 1.62 & 7.36 & 0.90 & 79.77 & 0.0583 & 0.0828 & 6 & 0.52 & 0.60 & 40.31 \\
\hline $\operatorname{Min}$ & 1.00 & 1.00 & 0.00 & -1.00 & 1.00 & 1.00 & 1.00 & -0.0024 & -0.1615 & 960 & 2.00 & 2.10 & 2.20 \\
\hline $\operatorname{Max}$ & 29.66 & 13.93 & 61.65 & 5.04 & 27.77 & 4.09 & 283.67 & 0.2032 & 0.1064 & 979 & 3.00 & 4.00 & 97.10 \\
\hline \multicolumn{14}{|c|}{ Panel C.- Consumer Services } \\
\hline Mean & 7.80 & 6.00 & 4.88 & 0.93 & 3.73 & 2.44 & 25.99 & -0.0000 & -0.0100 & 975 & 2.06 & 2.48 & 14.24 \\
\hline$S t d$ & 4.08 & 2.96 & 3.74 & 0.86 & 2.66 & 1.60 & 19.48 & 0.0065 & 0.0610 & 4 & 0.25 & 0.38 & 25.32 \\
\hline $\operatorname{Min}$ & 1.00 & 1.00 & 0.00 & -1.00 & 1.00 & 1.00 & 1.00 & -0.0151 & -0.1077 & 972 & 2.00 & 2.00 & 1.60 \\
\hline $\operatorname{Max}$ & 13.85 & 10.64 & 13.47 & 2.71 & 11.12 & 5.25 & 67.18 & 0.0143 & 0.1152 & 980 & 3.00 & 2.80 & 97.10 \\
\hline \multicolumn{14}{|c|}{ Panel D.- Financials } \\
\hline Mean & 22.21 & 7.97 & 27.52 & 1.42 & 5.28 & 2.86 & 147.55 & 0.0346 & 0.0450 & 974 & 2.50 & 2.61 & 6.83 \\
\hline Std & 22.44 & 3.95 & 34.50 & 0.90 & 5.42 & 2.18 & 187.21 & 0.0486 & 0.0620 & 5 & 0.63 & 0.53 & 7.22 \\
\hline $\operatorname{Min}$ & 5.56 & 4.04 & 2.79 & 0.16 & 1.65 & 1.00 & 17.33 & -0.0020 & -0.0959 & 961 & 2.00 & 2.00 & 0.90 \\
\hline $\operatorname{Max}$ & 93.50 & 17.85 & 132.36 & 4.37 & 24.81 & 7.40 & 710.13 & 0.1921 & 0.1553 & 980 & 4.00 & 3.90 & 22.80 \\
\hline \multicolumn{14}{|c|}{ Panel E.- Industrials } \\
\hline Mean & 31.37 & 14.44 & 31.64 & 1.00 & 3.15 & 5.18 & 136.69 & 0.0463 & -0.0032 & 972 & 2.46 & 2.77 & 8.35 \\
\hline$S t d$ & 46.06 & 17.74 & 64.23 & 0.35 & 1.08 & 7.21 & 259.50 & 0.1168 & 0.0734 & 7 & 0.52 & 0.75 & 11.82 \\
\hline $\operatorname{Min}$ & 3.76 & 1.72 & 2.91 & 0.53 & 2.07 & 1.00 & 13.72 & -0.0171 & -0.1017 & 959 & 2.00 & 2.00 & 0.60 \\
\hline $\operatorname{Max}$ & 170.16 & 66.45 & 241.75 & 1.89 & 5.92 & 27.38 & 977.33 & 0.4294 & 0.1358 & 980 & 3.00 & 4.10 & 38.50 \\
\hline \multicolumn{14}{|c|}{ Panel F.- Telecommunications } \\
\hline Mean & 7.66 & 5.03 & 6.00 & 0.77 & 3.14 & 1.52 & 24.79 & 0.0079 & -0.0502 & 969 & 2.58 & 3.08 & 12.80 \\
\hline$S t d$ & 3.72 & 1.78 & 4.59 & 0.83 & 3.28 & 0.87 & 16.92 & 0.0188 & 0.0515 & 10 & 0.51 & 0.97 & 13.05 \\
\hline $\operatorname{Min}$ & 1.65 & 1.11 & 0.83 & -0.36 & 1.78 & 1.00 & 3.85 & -0.0301 & -0.1453 & 949 & 2.00 & 2.00 & 3.10 \\
\hline $\operatorname{Max}$ & 13.71 & 7.42 & 15.00 & 3.05 & 13.47 & 3.15 & 54.68 & 0.0435 & 0.0258 & 980 & 3.00 & 5.10 & 48.40 \\
\hline \multicolumn{14}{|c|}{ Panel G.- Utilities } \\
\hline Mean & 11.23 & 5.11 & 10.30 & 1.11 & 5.60 & 2.16 & 47.91 & 0.0175 & -0.0384 & 973 & 2.57 & 2.74 & 10.51 \\
\hline$S t d$ & 5.71 & 1.95 & 7.06 & 0.92 & 12.16 & 1.34 & 42.06 & 0.0121 & 0.0712 & 4 & 0.51 & 0.45 & 9.64 \\
\hline $\operatorname{Min}$ & 5.28 & 2.06 & 2.15 & 0.57 & 1.70 & 1.00 & 10.00 & 0.0018 & -0.1744 & 963 & 2.00 & 2.00 & 2.40 \\
\hline $\operatorname{Max}$ & 26.68 & 8.64 & 26.43 & 4.25 & 47.81 & 4.48 & 168.59 & 0.0426 & 0.0589 & 980 & 3.00 & 3.70 & 26.00 \\
\hline \multicolumn{14}{|c|}{ Panel H.- Others (Health Care, Oil and Gas, and Technology) } \\
\hline Mean & 13.58 & 7.18 & 14.66 & 0.96 & 3.53 & 2.26 & 85.92 & 0.0050 & -0.0155 & 972 & 5.67 & 2.83 & 10.63 \\
\hline$S t d$ & 18.86 & 7.52 & 26.18 & 0.72 & 2.46 & 2.22 & 161.32 & 0.0093 & 0.0767 & 8 & 8.02 & 0.81 & 16.63 \\
\hline Min & 2.67 & 1.88 & 1.75 & 0.32 & 1.31 & 1.00 & 5.85 & -0.0054 & -0.1143 & 958 & 2.00 & 2.00 & 1.20 \\
\hline $\operatorname{Max}$ & 50.93 & 21.30 & 67.57 & 2.32 & 8.02 & 6.51 & 412.28 & 0.0223 & 0.1090 & 980 & 22.00 & 4.20 & 44.40 \\
\hline \multicolumn{14}{|c|}{ Panel I.- OVERALL } \\
\hline Mean & 14.45 & 6.84 & 15.68 & 1.12 & 4.88 & 2.50 & 83.33 & 0.0190 & -0.0139 & 973 & 2.43 & 2.72 & 14.50 \\
\hline$S t d$ & 21.79 & 7.84 & 32.26 & 1.13 & 8.41 & 3.17 & 186.82 & 0.0535 & 0.0706 & 6 & 0.52 & 0.62 & 22.07 \\
\hline Min & 1.00 & 1.00 & 0.00 & -1.00 & 1.00 & 1.00 & 1.00 & -0.0301 & -0.1744 & 949 & 2.00 & 2.00 & 0.60 \\
\hline $\operatorname{Max}$ & 170.16 & 66.45 & 241.75 & 7.32 & 61.51 & 27.38 & 1275.52 & 0.4294 & 0.1553 & 980 & 4.00 & 5.10 & 97.10 \\
\hline
\end{tabular}

This Table includes a summary of the main statistics for the 1-year EDF: the mean, median, standard deviation, skewness, kurtosis, minimum, maximum, mean of the differenced EDFs, 1st lag autocorrelation coefficient for the differenced EDFs, number of observations, longest series of consecutive missing EDFs, percentage of missing values, and percentage days with zero increments over the previous day. Our sample consists of daily EDFs for 95 European firms included in the Markit's database, covering from 01/Jun/2006 to 31/Mar/2010. 
Table 5: Panel Regressions.

The specification of linear models I to IV is represented as

$$
Y_{i t}=\beta_{0}+D_{\text {dummy }}+\beta_{1} X_{i t}+\beta_{1}^{\prime} D_{\text {dummy }} X_{i t}+\varepsilon_{i t}
$$

Additionally, the specifications for the linear in logs (log-log) models V-VIII is represented as

$$
Y_{i t}=e^{\left[\beta_{0}+D_{\text {dummy }}\right]} \cdot X_{i t}^{\left[\beta_{1}+\beta_{1}^{\prime} D_{\text {dummy }}\right]} \cdot \varepsilon_{i t}
$$

where subscripts $i, t$ stand for firm and time, respectively. Variable $D$ is a dummy variable and variable $D_{\text {period\# }} \times E D F 5 y$ stands for the interaction effect between the dummy variable corresponding to period \# and the variable $E D F 5 y$. The sample consists of 91,682 observations of daily 5-year CDS spreads and EDF rates for 95 European firms included in the Markit's database, covering from 01/Jun/2006 to 31/Mar/2010. Period 1 goes from 01/Jun/2006 to 08/Aug/2007, period 2 goes from 09/Aug/2007 to 07/Oct/2008, and

\begin{tabular}{|c|c|c|c|c|c|c|c|c|}
\hline \multirow{3}{*}{$\begin{array}{l}\text { Dependent variable } \\
\text { Model }\end{array}$} & \multicolumn{8}{|c|}{ CDS5y } \\
\hline & \multicolumn{4}{|c|}{ Levels } & \multicolumn{4}{|c|}{$\log s$} \\
\hline & (I) & (II) & (III) & (IV) & (V) & (VI) & (VII) & (VIII) \\
\hline Cons. & $\begin{array}{r}0.006754 \\
(0.000)\end{array}$ & $\begin{array}{r}0.041771 \\
(0.000)\end{array}$ & $\begin{array}{r}0.036402 \\
(0.000)\end{array}$ & $\begin{array}{r}-0.038866 \\
(0.000)\end{array}$ & $\begin{array}{r}-2.874388 \\
(0.000)\end{array}$ & $\begin{array}{r}13.054945 \\
(0.000)\end{array}$ & $\begin{array}{r}9.036183 \\
(0.000)\end{array}$ & $\begin{array}{r}-8.252234 \\
(0.000)\end{array}$ \\
\hline EDF5y & $\begin{array}{r}0.438403 \\
(0.000)\end{array}$ & $\begin{array}{r}0.371357 \\
(0.000)\end{array}$ & $\begin{array}{r}0.498652 \\
(0.000)\end{array}$ & $\begin{array}{r}0.585698 \\
(0.000)\end{array}$ & $\begin{array}{r}0.353022 \\
(0.000)\end{array}$ & $\begin{array}{r}0.256780 \\
(0.000)\end{array}$ & $\begin{array}{r}0.510290 \\
(0.000)\end{array}$ & $\begin{array}{r}0.257688 \\
(0.000)\end{array}$ \\
\hline LIQ5y & & $\begin{array}{r}-0.001734 \\
(0.000)\end{array}$ & $\begin{array}{r}-0.001212 \\
(0.000)\end{array}$ & $\begin{array}{r}-0.001772 \\
(0.000)\end{array}$ & & $\begin{array}{r}-2.999071 \\
(0.000)\end{array}$ & $\begin{array}{r}-3.219620 \\
(0.000)\end{array}$ & $\begin{array}{r}-2.999676 \\
(0.000)\end{array}$ \\
\hline LIQEU5y & & $\begin{array}{r}-0.001969 \\
(0.000)\end{array}$ & $\begin{array}{r}-0.002302 \\
(0.000)\end{array}$ & $\begin{array}{r}0.005670 \\
(0.000)\end{array}$ & & $\begin{array}{r}-4.383107 \\
(0.000)\end{array}$ & $\begin{array}{r}-1.889128 \\
(0.000)\end{array}$ & $\begin{array}{r}4.816496 \\
(0.000)\end{array}$ \\
\hline$D_{\text {Period } 2} \times$ EDF5y & & & & $\begin{array}{r}0.641526 \\
(0.000)\end{array}$ & & & & $\begin{array}{r}0.154647 \\
(0.000)\end{array}$ \\
\hline$D_{\text {Period } 3} \times \mathrm{EDF} 5 \mathrm{y}$ & & & & $\begin{array}{r}-0.369647 \\
(0.000)\end{array}$ & & & & $\begin{array}{r}-0.015576 \\
(0.000)\end{array}$ \\
\hline$D_{\text {Period }}$ & No & No & No & Yes & No & No & No & Yes \\
\hline$D_{\text {Country }}$ & No & No & Yes & Yes & No & No & Yes & Yes \\
\hline$D_{\text {Sector }}$ & No & No & Yes & Yes & No & No & Yes & Yes \\
\hline$D_{\text {Av.Rating }}$ & No & No & Yes & Yes & No & No & Yes & Yes \\
\hline$D_{\text {Firm }}$ & No & No & Yes & Yes & No & No & Yes & Yes \\
\hline Obs. & 92336 & 91682 & 91682 & 91682 & 92336 & 91682 & 91682 & 91682 \\
\hline$R^{2}$-Adj & 0.0822 & 0.1684 & 0.3439 & 0.4994 & 0.2229 & 0.5211 & 0.7092 & 0.8242 \\
\hline
\end{tabular}
period 3 goes from 08/Oct/2008 to 31/Mar/2010. 
Table 6: Projections of sample values onto fitted values

\begin{tabular}{|c|c|c|c|c|c|c|}
\hline \multirow[b]{2}{*}{ Maturity } & \multicolumn{6}{|c|}{$\Delta s_{t}^{\text {sample }}=\beta_{0}+\beta_{1} \Delta s_{t}^{\text {theo }}+\varepsilon_{t}$} \\
\hline & $\hat{\beta_{0}}$ & $\hat{\beta}_{0}$ & $R^{2}$ & std. res. (bps) & D.W. & $\mathrm{N}$ \\
\hline \multicolumn{7}{|c|}{ Panel A: Sample CDS spreads onto fitted CDS spreads } \\
\hline 1 Year & $\begin{array}{c}0 \\
(0.00)\end{array}$ & $\begin{array}{c}1.0203 \\
(0.0014)\end{array}$ & 0.85 & 2.4446 & $\begin{array}{l}2.5325 \\
(0.00)\end{array}$ & 93200 \\
\hline 3 Year & $\begin{array}{c}0 \\
(0.00)\end{array}$ & $\begin{array}{c}0.8656 \\
(0.0015)\end{array}$ & 0.79 & 2.5400 & $\begin{array}{c}2.4184 \\
(0.00)\end{array}$ & 93200 \\
\hline 5 Year & $\begin{array}{c}0 \\
(0.00)\end{array}$ & $\begin{array}{c}0.8078 \\
(0.0017)\end{array}$ & 0.72 & 2.9611 & $\begin{array}{c}2.1644 \\
(0.00)\end{array}$ & 93200 \\
\hline Overall & $\begin{array}{c}0 \\
(0.00) \\
\end{array}$ & $\begin{array}{c}0.8976 \\
(0.0009) \\
\end{array}$ & 0.79 & 2.7082 & $\begin{array}{c}2.3950 \\
(0.00) \\
\end{array}$ & 279600 \\
\hline \multicolumn{7}{|c|}{ Panel B: Sample EDF onto fitted EDF } \\
\hline 1 Year & $\begin{array}{c}0 \\
(0.00)\end{array}$ & $\begin{array}{c}3.2587 \\
(0.0047)\end{array}$ & 0.84 & 2.4252 & $\begin{array}{c}2.0931 \\
(0.00)\end{array}$ & 93200 \\
\hline 3 Year & $\begin{array}{c}0 \\
(0.00)\end{array}$ & $\begin{array}{c}1.2396 \\
(0.0007)\end{array}$ & 0.97 & 0.9588 & $\begin{array}{c}2.1196 \\
(0.00)\end{array}$ & 93200 \\
\hline 5 Year & $\begin{array}{c}0 \\
(0.00)\end{array}$ & $\begin{array}{c}0.7712 \\
(0.0002)\end{array}$ & 0.99 & 0.4387 & $\begin{array}{l}2.0327 \\
(0.00)\end{array}$ & 93200 \\
\hline Overall & $\begin{array}{c}0 \\
(0.00)\end{array}$ & $\begin{array}{c}0.9833 \\
(0.0010)\end{array}$ & 0.76 & 2.9216 & $\begin{array}{c}2.1337 \\
(0.00)\end{array}$ & 279600 \\
\hline
\end{tabular}

This Table shows the projections of CDS and EDF data onto their model counterparts, respectively. Standard deviation of residuals (std. res.) is given in basic points. Durbin-Watson statistic (D.W.) is also provided. P-values are in parentheses. 


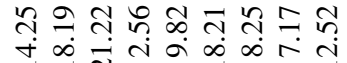
-

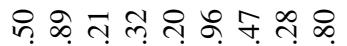

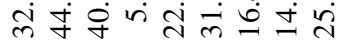

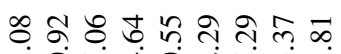

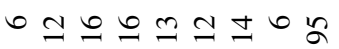

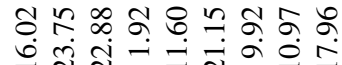

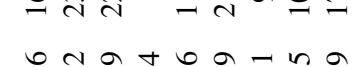

ํㅗㄹ

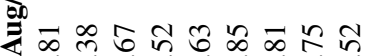

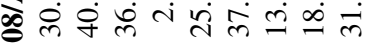

ठั้

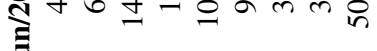

窝

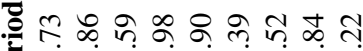

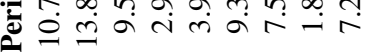

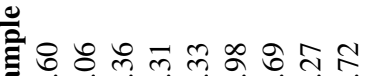

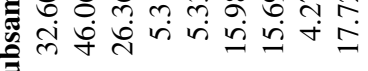

की

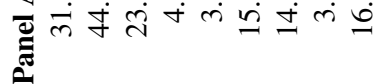

$N$ n $N$ m $m$ 으 $N$

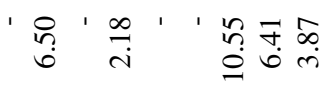

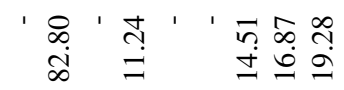

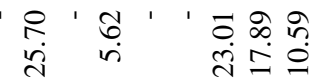

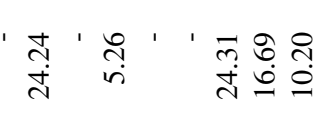

'

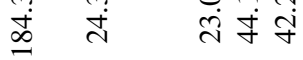

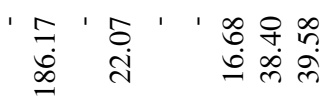

O-ONOO--

ororoon-?

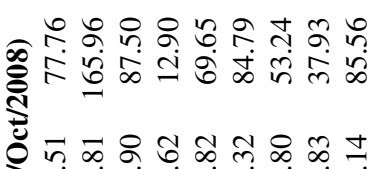

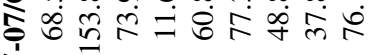

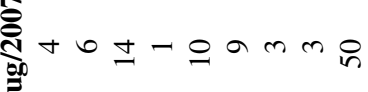

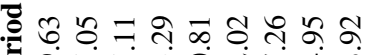

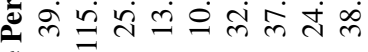

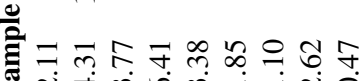

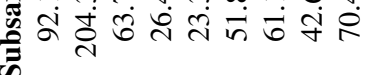

แ่

चूّ

$N$ in $N$ m m 으 $N$

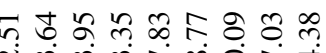

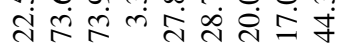

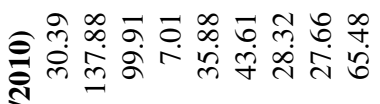

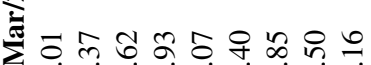

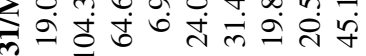

仓ั.

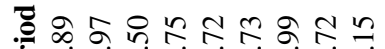

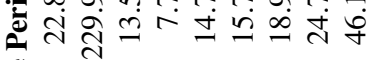

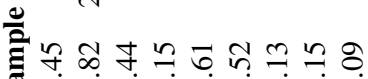

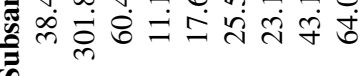

ப்

चे ले के

Nin $N$ m n 으묘

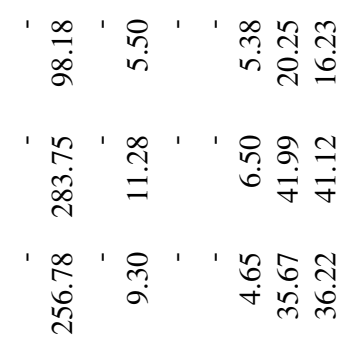

o-oroon-O

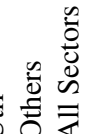

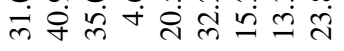

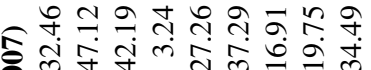

m

भुष्ठ

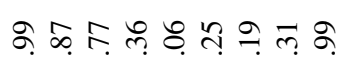

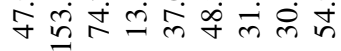

ลู่

तี

ㅁํํำェำ

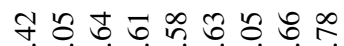

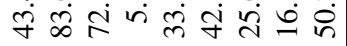

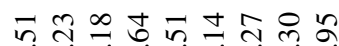

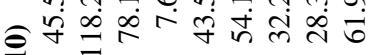

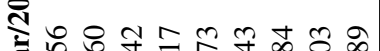

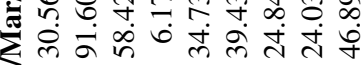

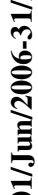

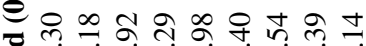

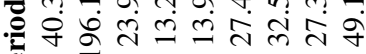

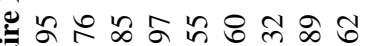
ज्ञ ๑ิ்

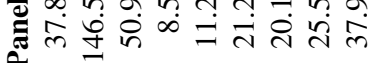
Nin $N m m$ 의

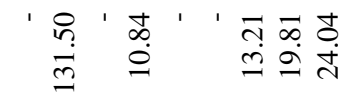

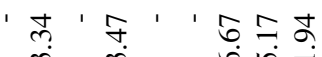
$\cong \quad \stackrel{\dot{m} m}{=}$

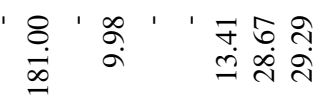
omoroonto 華节 莡过 空击

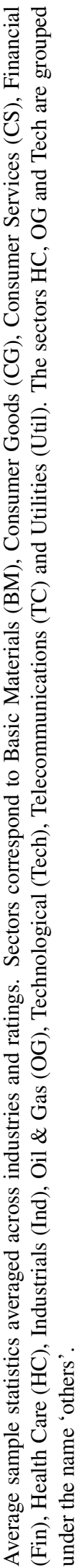


Table 8: Principal components analysis of risk premia, CDS and EDF.

\begin{tabular}{|c|c|c|c|c|c|c|c|c|c|c|}
\hline & \multicolumn{5}{|c|}{ Levels (\%) } & \multicolumn{5}{|c|}{ First Differences (\%) } \\
\hline & PC1 & PC2 & PC3 & PC4 & Cum Var & PC1 & PC2 & PC3 & PC4 & Cum Var \\
\hline RP & 56.01 & 14.88 & 5.37 & 4.39 & 80.65 & 19.73 & 7.43 & 3.80 & 3.35 & 34.31 \\
\hline CDS1y & 90.56 & 3.73 & 1.44 & 0.91 & 96.64 & 30.16 & 3.43 & 2.82 & 2.64 & 39.05 \\
\hline CDS3y & 87.50 & 4.31 & 2.75 & 1.09 & 95.65 & 49.58 & 4.97 & 2.51 & 2.34 & 59.40 \\
\hline CDS5y & 82.50 & 5.42 & 4.34 & 1.38 & 93.64 & 55.98 & 4.98 & 2.59 & 2.20 & 65.75 \\
\hline EDF1y & 67.20 & 9.07 & 7.15 & 3.78 & 87.20 & 28.23 & 6.11 & 4.87 & 4.40 & 43.61 \\
\hline EDF3y & 68.20 & 8.93 & 6.82 & 3.43 & 87.38 & 29.04 & 6.16 & 4.96 & 4.38 & 44.54 \\
\hline EDF5y & 70.26 & 8.82 & 6.43 & 3.15 & 88.66 & 29.60 & 6.52 & 4.82 & 4.47 & 45.41 \\
\hline
\end{tabular}

Explanatory power of first four Principal Components for risk premium, CDS and EDF, respectively.

Table 9: Statistics for 5-year Sovereign CDS spreads

\begin{tabular}{llrrrrrrr}
\hline Country & Av. Rating & $\begin{array}{r}\text { SOVPC1 } \\
\text { Loading }\end{array}$ & $\begin{array}{r}\text { SOVPC2 } \\
\text { Loading }\end{array}$ & $\begin{array}{c}\text { Mean } \\
\text { (bps) }\end{array}$ & $\begin{array}{r}\text { Median } \\
\text { (bps) }\end{array}$ & $\begin{array}{r}\text { Std } \\
\text { (bps) }\end{array}$ & $\begin{array}{c}\text { Min } \\
\text { (bps) }\end{array}$ & $\begin{array}{c}\text { Max } \\
\text { (bps) }\end{array}$ \\
\hline \hline Austria & AAA & 0.26 & 0.18 & 41.9212 & 9.5278 & 55.1059 & 1.4929 & 268.8790 \\
Belgium & AA & 0.26 & 0.03 & 30.5537 & 20.1558 & 33.4465 & 1.9257 & 155.5260 \\
Denmark & AAA & 0.25 & 0.29 & 26.1043 & 8.7178 & 34.8324 & 1.2018 & 146.5288 \\
Finland & AAA & 0.26 & 0.16 & 17.0224 & 8.7432 & 19.6804 & 1.0833 & 92.2308 \\
France & AAA & 0.26 & -0.07 & 19.5718 & 10.1011 & 21.6888 & 1.4698 & 97.8750 \\
Germany & AAA & 0.26 & 0.05 & 16.5201 & 6.7374 & 18.9517 & 1.2922 & 91.3750 \\
Greece & BBB & 0.23 & -0.55 & 89.8424 & 47.0909 & 100.6981 & 4.7171 & 425.1830 \\
Ireland & AA & 0.26 & 0.06 & 76.3738 & 24.7737 & 91.6812 & 1.6667 & 384.3440 \\
Italy & AA & 0.26 & -0.07 & 54.7276 & 38.4226 & 52.4401 & 5.2910 & 197.7844 \\
Netherlands & AAA & 0.26 & 0.22 & 23.0851 & 8.7989 & 29.6164 & 1.1286 & 127.8311 \\
Norway & AAA & 0.25 & 0.24 & 12.6074 & 5.9558 & 13.7902 & 1.1737 & 63.6294 \\
Portugal & A & 0.24 & -0.50 & 45.2454 & 34.8704 & 44.7074 & 3.8640 & 245.2152 \\
Spain & AA & 0.25 & -0.32 & 46.2481 & 33.2419 & 44.9890 & 2.3483 & 171.7511 \\
Sweden & AAA & 0.25 & 0.22 & 29.6170 & 8.6600 & 37.5976 & 1.3125 & 158.4394 \\
United Kingdom & AA & 0.26 & -0.03 & 36.2298 & 14.2855 & 42.0654 & 1.1995 & 164.6300 \\
\hline
\end{tabular}

We consider sovereign CDS spreads for all Western European countries with firms included in the Markit's database with available data for all the sample period. The sovereign CDS contracts are denominated in U.S. dollars under Old Restructuring clause. The first component SOVPC1 explains a $93.37 \%$ of the variability, and the second component SOVPC2 explains a $4.45 \%$. 
Table 10: Unit Root Test Statistics

\begin{tabular}{lrrrrr}
\hline \hline & \multicolumn{2}{c}{ Levels } & & \multicolumn{2}{c}{ First differences } \\
\cline { 2 - 3 } \cline { 6 - 7 } & ADF & PP & & ADF & PP \\
\hline logLIQEU5y & $-0,942$ & $-1,094$ & & $-6,903^{* * *}$ & $-30,010^{* * *}$ \\
$\operatorname{logESTOXX50~}$ & $-0,890$ & $-0,951$ & & $-6,744^{* * *}$ & $-34,122^{* * *}$ \\
$\log$ VIX & $-1,755$ & $-1,948$ & & $-7,211^{* * *}$ & $-37,888^{* * *}$ \\
$\log$ loSD/EUR & $-2,168$ & $-1,970$ & & $-6,286^{* * *}$ & $-31,187^{* * *}$ \\
logEONIA & 0,767 & $-0,028$ & & $-7,621^{* * *}$ & $-64,360^{* * *}$ \\
SLOPE & -0.309 & -0.104 & & $-6.437^{* * *}$ & $-29.302^{* * *}$ \\
$\log 3$ M-EURIBOR-OIS & $-1,384$ & $-1,632$ & & $-6,148^{* * *}$ & $-39,098^{* * *}$ \\
$\operatorname{logFPWE5y~}$ & $-0,998$ & $-0,846$ & & $-3,899^{* * *}$ & $-9,666^{* * *}$ \\
SOVPC1 & -1.374 & -1.289 & & $-6.608^{* * *}$ & $-20.274^{* * *}$ \\
SOVPC2 & -0.489 & -0.280 & & $-6.523^{* * *}$ & $-29.625^{* * *}$ \\
\hline
\end{tabular}

ADF refers to the augmented Dickey-Fuller unit root test. PP stands for the Phillis-Perron unit root test. Both cases under the alternative of an autoregressive with drift. The number of lag-length $p$ of the autoregressive employed is 20 following Schwert's formula: $p=\operatorname{int}\left\{12(N / 100)^{(1 / 4)}\right\}$, where $N$ is the number of observations, and int stands for the integer part. The superscripts $\{*, * *, * * *\}$ indicate statistical significance at $10 \%, 5 \%$, and $1 \%$ respectively. 
Table 11: Dynamic panel regression for $\Delta \operatorname{logRP}{ }_{i, t}$

The baseline model for our dynamic panel regression is

$$
\Delta Y_{i, t}=D_{\text {dummy }}+\beta_{1} \Delta Y_{i, t-1}+\beta_{2} X_{i, t-1}+\beta_{3} Z_{t-1}+\varepsilon_{i, t}
$$

Since no integrated variables can enter the equation, all exogenous variables $X$ and $Z$ with unit roots are differenced until they get stationary. The coefficients are estimated by OLS. The p-values reported come from clustered standard errors by firm and by time, as suggested by Petersen (2009) to correct the fact that the residuals may be correlated across firms or across time. The date 09/Aug/2007 refers to the day that BNP Paribas froze three investment funds, and 08/Oct/2008 refers to the date that the ECB increased the lending aid to financial institutions.

\begin{tabular}{|c|c|c|c|c|}
\hline \multirow{3}{*}{$\begin{array}{l}\text { Dependent variable } \\
\text { Model }\end{array}$} & \multicolumn{4}{|c|}{$\Delta \log \mathrm{RP}_{i, t}$} \\
\hline & (I) & (II) & (III) & $\overline{(I V)}$ \\
\hline & $<09 /$ Aug/2007 & $\begin{array}{r}\geq 09 / \text { Aug/2007 } \\
<08 / \text { Oct } / 2008\end{array}$ & $\geq 08 /$ Oct $/ 2008$ & All period \\
\hline \multirow[t]{2}{*}{$\Delta \log R P_{i, t-1}$} & -0.092550 & -0.007965 & -0.018555 & -0.038260 \\
\hline & $(0.000)$ & $(0.551)$ & $(0.226)$ & $(0.001)$ \\
\hline \multirow[t]{2}{*}{$\Delta \operatorname{logLIQ} 5 y_{i, t-1}$} & -0.048503 & 0.001277 & -0.108978 & -0.048333 \\
\hline & $(0.623)$ & (0.992) & $(0.362)$ & $(0.501)$ \\
\hline \multirow[t]{2}{*}{$\Delta \log L I Q E U 5 y_{t-1}$} & 0.260532 & 0.422956 & 0.733834 & 0.538934 \\
\hline & $(0.755)$ & (0.419) & $(0.123)$ & $(0.131)$ \\
\hline \multirow[t]{2}{*}{$\Delta \operatorname{logESTOXX50} 0_{t-1}$} & -0.160279 & -0.356858 & -0.509636 & -0.427112 \\
\hline & $(0.526)$ & $(0.037)$ & $(0.000)$ & $(0.000)$ \\
\hline \multirow[t]{2}{*}{$\Delta \log \mathrm{VIX}_{t-1}$} & 0.004383 & 0.062786 & -0.065623 & 0.004793 \\
\hline & $(0.896)$ & $(0.048)$ & $(0.099)$ & $(0.835)$ \\
\hline \multirow[t]{2}{*}{$\Delta \log U S D / E R_{t-1}$} & -0.257259 & 0.705508 & 0.468796 & 0.509814 \\
\hline & $(0.595)$ & $(0.048)$ & $(0.033)$ & $(0.005)$ \\
\hline \multirow[t]{2}{*}{$\Delta \log \mathrm{EONIA}_{t-1}$} & 0.147666 & -0.032444 & -0.011688 & -0.008837 \\
\hline & $(0.039)$ & $(0.657)$ & $(0.202)$ & $(0.306)$ \\
\hline \multirow[t]{2}{*}{$\Delta \mathrm{SLOPE}_{t-1}$} & -0.077559 & 0.096468 & -0.061611 & 0.018521 \\
\hline & $(0.496)$ & (0.137) & $(0.213)$ & $(0.638)$ \\
\hline \multirow{2}{*}{$\Delta \log 3 \mathrm{M}-E U R I B O R-O S_{t-1}$} & -0.009974 & -0.000993 & 0.070492 & -0.003805 \\
\hline & $(0.535)$ & (0.974) & $(0.174)$ & $(0.789)$ \\
\hline \multirow[t]{2}{*}{$\Delta \operatorname{logFPWE} 5 \mathrm{y}_{t-1}$} & 0.377051 & 0.153816 & 0.526230 & 0.373926 \\
\hline & $(0.043)$ & $(0.557)$ & $(0.020)$ & $(0.004)$ \\
\hline \multirow[t]{2}{*}{$\Delta \mathrm{SOVPC}_{t-1}$} & 2.020050 & -0.000246 & 0.009527 & 0.012837 \\
\hline & $(0.001)$ & $(0.995)$ & (0.137) & $(0.037)$ \\
\hline \multirow[t]{2}{*}{$\Delta \mathrm{SOVPC} 2_{t-1}$} & -2.862911 & -0.149509 & -0.023462 & -0.018237 \\
\hline & $(0.000)$ & (0.184) & (0.092) & (0.183) \\
\hline$D_{\text {Country }}$ & Yes & Yes & Yes & Yes \\
\hline$D_{\text {Sector }}$ & Yes & Yes & Yes & Yes \\
\hline$D_{\text {Av.Rating }}$ & Yes & Yes & Yes & Yes \\
\hline$D_{\text {Firm }}$ & Yes & Yes & Yes & Yes \\
\hline Obs. & 25794 & 26868 & 34032 & 86694 \\
\hline$R^{2}$-Adj & 0.0239 & 0.0176 & 0.0293 & 0.0138 \\
\hline $\mathrm{AIC}$ & -42565.53 & -52341.44 & -73257.53 & -165234.52 \\
\hline BIC & -42451.32 & -52234.85 & -73147.87 & -165112.71 \\
\hline
\end{tabular}


Table 12: Granger causality Wald tests for $\operatorname{VAR}(\mathrm{p}=6)$

\begin{tabular}{lclrrr}
\hline Equation & \multicolumn{1}{c}{$R^{2}$} & Excluded & $\chi^{2}$ & df & Prob $>\chi^{2}$ \\
\hline \hline$\Delta$ RPPC1 & & $\Delta$ RPPC2 & 11.44 & 6 & 0.076 \\
$\Delta$ RPPC1 & & $\Delta \operatorname{logESTOXX50~}$ & 81.559 & 6 & 0.000 \\
$\Delta$ RPPC1 & 0.1965 & $\Delta \operatorname{logUSD/EUR~}$ & 15.921 & 6 & 0.014 \\
$\Delta$ RPPC1 & & $\Delta \operatorname{logFPWE5y}$ & 1.0821 & 6 & 0.982 \\
$\Delta$ RPPC1 & $\Delta$ SOVPC1 & .96135 & 6 & 0.987 \\
$\Delta$ RPPC1 & ALL & 173.47 & 30 & 0.000 \\
\hline$\Delta$ RPPC2 & $\Delta$ RPPC1 & 9.2922 & 6 & 0.158 \\
$\Delta$ RPPC2 & $\Delta \operatorname{logESTOXX50~}$ & 10.495 & 6 & 0.105 \\
$\Delta$ RPPC2 & 0.1075 & $\Delta \operatorname{logUSD} /$ EUR & 3.1224 & 6 & 0.793 \\
$\Delta$ RPPC2 & & $\Delta \operatorname{logFPWE5y}$ & 13.316 & 6 & 0.038 \\
$\Delta$ RPPC2 & & $\Delta$ SOVPC1 & 20.812 & 6 & 0.002 \\
$\Delta$ RPPC2 & ALL & 80.179 & 30 & 0.000 \\
\hline
\end{tabular}

Results for a VAR model with 6 lagged variables according the likelihood-ratio test. Our sample is composed by 960 observations. The sample period comprises from 01/Jun/2006 to 31/Mar/2010. 
Figure 1: Distribution of risk premium along time
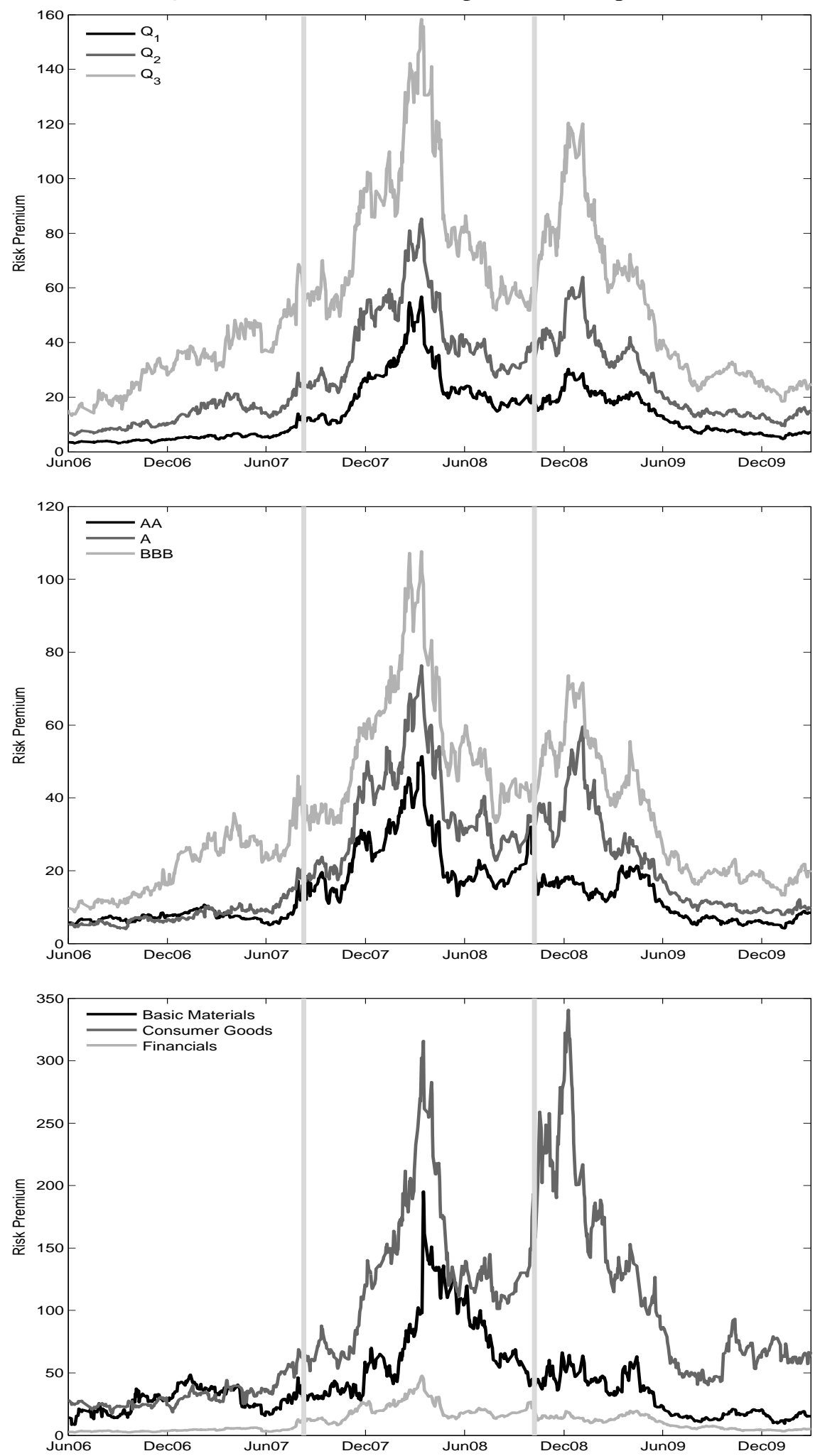

This Figure shows the evolution through time of risk premia over time by quartiles (upper graph), ratings (medium graph) and sectors (bottom graph), respectively. Rating and sector figures display the median statistic for each day. The period comprises from 01/Jun/2006 to 31/Mar/2010. Vertical bars indicate the subsample periods. 
Figure 2: Principal components of risk premium against financial variables over time
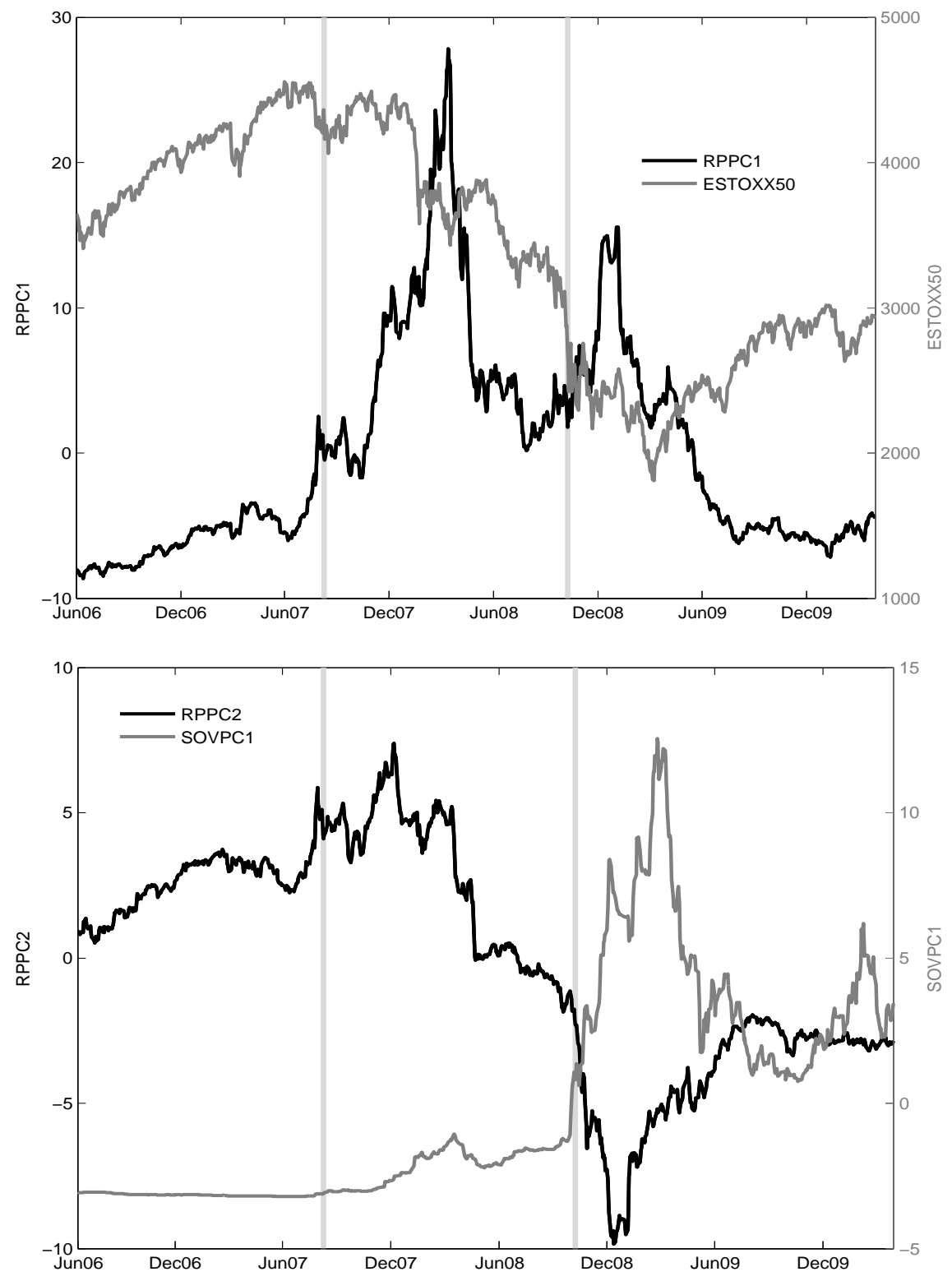

This Figure shows the evolution through time of first component (RPPC1, upper graph) and second component (RPPC2, bottom graph) of risk premium over time with market index (ESTOXX50) and first component of sovereign CDS, respectively. The period comprises from 01/Jun/2006 to 31/Mar/2010. Vertical bars indicate the subsample periods. 
Figure 3: Impulse-response graphs for Vector Autoregressive model

(a) Impulse $\left(\Delta \operatorname{logESTOXX} 50_{t=0}\right)$, Response $\left(\Delta \mathrm{RPPC}_{t}\right)$

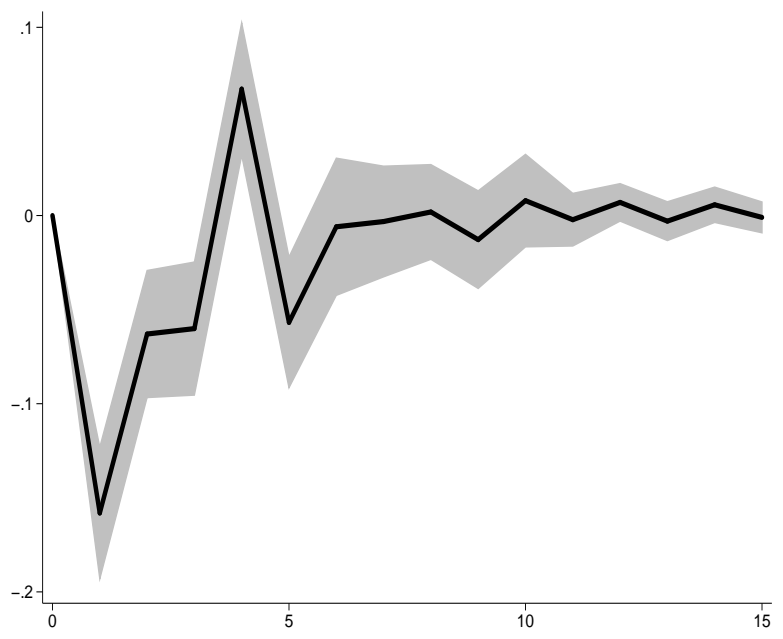

(c) Impulse $\left(\Delta \log F P W E 05 y_{t=0}\right)$, Response $\left(\Delta \mathrm{RPPC} 2_{t}\right)$

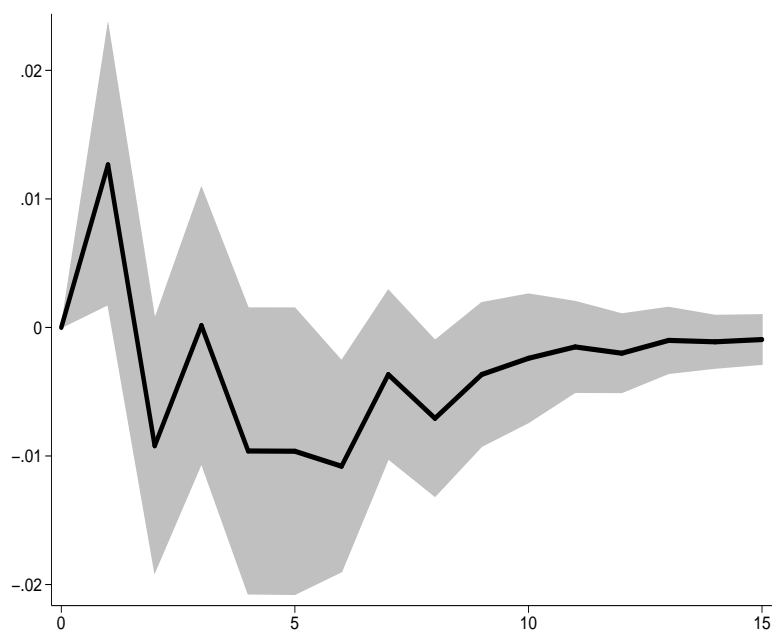

(b) Impulse $\left(\Delta \log U S D / E R_{t=0}\right), \operatorname{Response}\left(\Delta \mathrm{RPPC1}_{t}\right)$

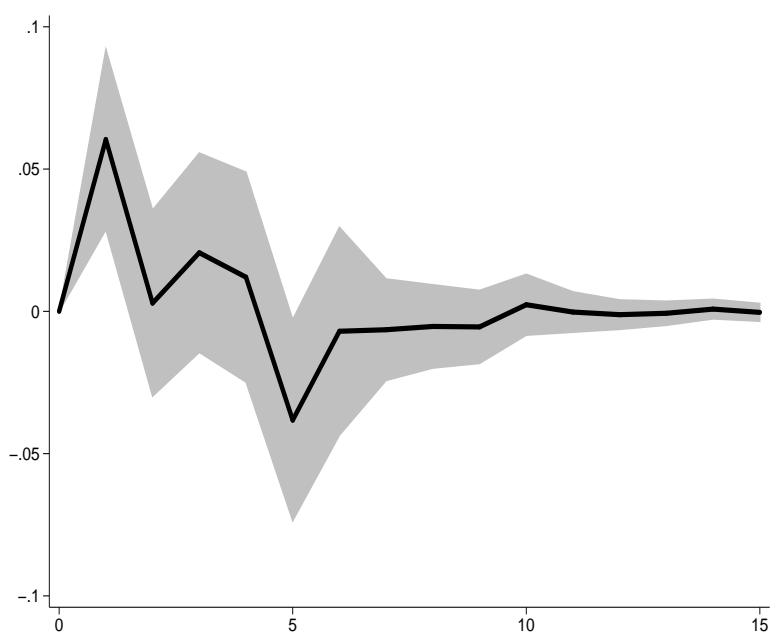

(d) Impulse $\left(\Delta \mathrm{SOVPC} 1_{t=0}\right), \operatorname{Response}\left(\Delta \mathrm{RPPC} 2_{t}\right)$

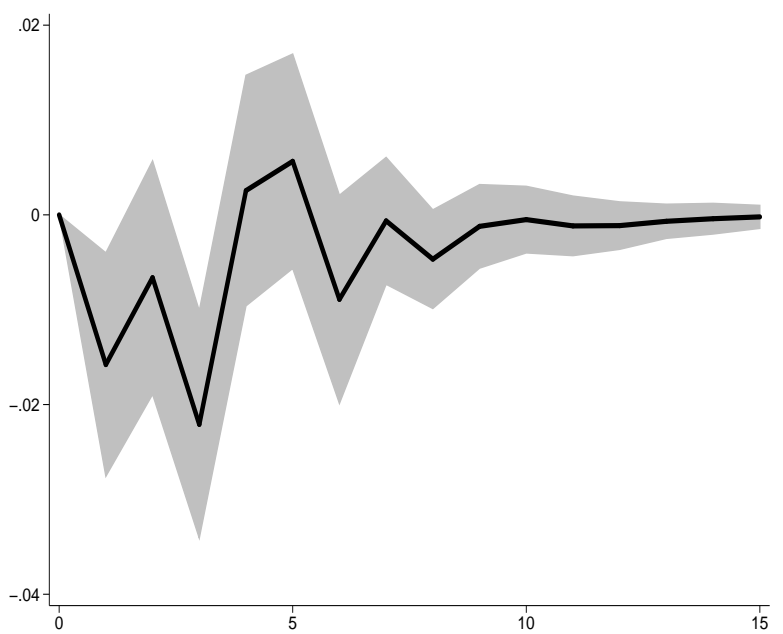

Orthogonalized impulse-response function through time to shocks at $t=0$. Upper figures display the response of first principal component of risk premium $(\triangle \mathrm{RPPC} 1)$ to changes in stock (a) and exchange (b) markets. Bottom figures depicts the response of second principal component of risk premium $(\triangle \mathrm{RPPC} 2)$ to changes in systemic risk (c) and sovereign default (d) variables. The shaded area corresponds to $95 \%$ confidence interval obtained with bootstrapped standard errors. 